\title{
Acute regulation of murine follicle-stimulating hormone $\beta$ subunit transcription by activin $\mathrm{A}$
}

\author{
Pankaj Lamba, Michelle M Santos, Daniel P Philips and Daniel J Bernard
}

Center for Biomedical Research, Population Council and The Rockefeller University, 1230 York Avenue, New York, New York 10021, USA

(Requests for offprints should be addressed to D J Bernard; Email: dbernard@ popcbr.rockefeller.edu)

\begin{abstract}
In rodents, activins stimulate immediate-early increases in pituitary follicle-stimulating hormone $\beta$ (Fshb) subunit transcription. Here, we investigated the underlying signaling mechanisms using the mouse gonadotrope cell line, L $\beta$ T2. Activin A increased mouse Fshb-luciferase reporter activity within $4 \mathrm{~h}$ through a Smad-dependent signaling pathway. The ligand rapidly stimulated formation of SMAD2/3/4 complexes that could interact with a consensus palindromic Smad binding element (SBE) in the proximal Fshb promoter. SMAD over-expression potently stimulated transcription, with the combination of SMADs 2, 3 and 4 producing the greatest synergistic activation. A mutation in the SBE that abolished Smad binding greatly impaired the effects of acute $(4 \mathrm{~h})$ activin A treatment and SMAD over-expression on promoter activity, but did not abolish the effects of chronic $(24 \mathrm{~h})$ activin A exposure. Within activated SMAD complexes, SMADs 3 and 4 appeared to bind the SBE simultaneously and the binding of both was required for maximal transcriptional activation. Interestingly, the human FSHB promoter, which lacks the consensus SBE, was neither rapidly stimulated by activin A nor by over-expressed SMADs, but was activated by $24 \mathrm{~h}$ activin $\mathrm{A}$. Addition of the SBE to the human promoter increased both SMAD2/3/4-sensitivity and acute regulation by activin $A$, though not to levels observed in mouse. We postulate that short reproductive cycles in female rodents, particularly the brief interval between the primary and secondary FSH surges of the estrous cycle, require the Fshb promoter in these animals to be particularly sensitive to the rapid, Smad-dependent actions of activins on transcription. The human FSHB promoter, in contrast, is chronically regulated by activins seemingly through a SMAD-independent pathway.
\end{abstract}

Journal of Molecular Endocrinology (2006) 36, 201-220

\section{Introduction}

In female mammals, proper regulation of folliclestimulating hormone (FSH) synthesis, secretion and action is critical for the maintenance of normal reproduction (Layman \& McDonough 2000, Themmen \& Huhtaniemi 2000). Across the 4 to 5 days of rodent estrous cycles, there are two peaks in FSH release from gonadotrope cells of the anterior pituitary gland. The primary FSH surge occurs coincidentally with the release of luteinizing hormone $(\mathrm{LH})$ on the afternoon of proestrus as a result of increases in amplitude and frequency of gonadotropin-releasing hormone secretion from the pre-optic area/hypothalamus (Levine 1997). In rats, the secondary FSH surge occurs independently of changes in LH secretion and peaks only $10-12 \mathrm{~h}$ after the primary surge, on the morning of estrus (Woodruff et al. 1996, Besecke et al. 1997, Ortolano et al. 1988, Chapman \& Woodruff 2003). Although there are fewer data in mice, the pattern of FSH release across their estrous cycles appears to be very similar (Nequin $e t$ al. 1979, Tejada et al. 1998, Huang et al. 2001, Ahn et al. 2004). Whereas the primary FSH surge has limited or no functional relevance (DePaolo et al. 1979, Hoffmann et al. 1979), the secondary surge is fundamentally required for persistent cycles of ovarian follicle selection and maturation (DePaolo et al. 1979, Hoak \& Schwartz 1980). Given their relative physiological importance, it is noteworthy that the primary surge in rats depletes intra-pituitary FSH stores (Ortolano et al. 1988, Chapman \& Woodruff 2003). This presents the animals with the physiological challenge of generating new FSH within a rapid enough time frame to mount the secondary surge.

One way in which they meet this challenge is through an acute and robust increase in expression of the $\beta$ subunit of dimeric FSH $(F s h)$, the rate-limiting step in mature hormone synthesis. In rats, increases in Fshb mRNA levels in the pituitary parallel and temporally precede increases in FSH release during the secondary surge (Ortolano et al. 1988, Halvorson et al. 1994). At the same time there is no increase in intra-pituitary FSH content, suggesting that the newly synthesized Fshb mRNA is quickly translated, linked to the glycoprotein hormone $\alpha$ subunit and constitutively released as mature hormone (Nicol et al. 2004). Arguably, intra-pituitary activins provide the major stimulus for FSH synthesis during this stage of the rodent estrous cycle. Indeed, 
changes in hormonal milieu (e.g. declines in serum inhibins and intra-pituitary follistatins) following the primary surge provide a permissive environment for locally produced activins to rapidly stimulate increases in Fshb transcription and thereby to generate the secondary surge on estrus morning (Woodruff et al. 1996, Besecke et al. 1997).

Activins selectively regulate FSH production and secretion from gonadotrope cells (Bilezikjian et al. 2004, Gregory \& Kaiser 2004). The ligands are members of the TGFB superfamily and come in three forms through the disulfide linking of two related $\beta$ subunits: activin A (INHBA-INHBA), activin B (INHBB-INHBB), and activin $\mathrm{AB}$ (INHBA-INHBB). Both the Inhba and Inhbb subunit genes are expressed in rat pituitary gland (Halvorson et al. 1994) and in gonadotropes in particular (Roberts et al. 1989), though activin B appears to be the predominant autocrine/paracrine acting form of the ligand in these cells (Corrigan et al. 1991). In primary rat pituitary cultures, recombinant activin A stimulates rapid increases in Fshb mRNA levels and FSH secretion (Carroll et al. 1989, Attardi \& Miklos 1990, Weiss et al. 1995), whereas immuno-neutralization of endogenous activin B suppresses FSH release (Corrigan et al. 1991). Moreover, treatment of cycling rats with an activin B monoclonal antibody blunts the secondary surge, strongly implicating the endogenous ligand in the process in vivo (DePaolo et al. 1992).

Like other members of the TGFB superfamily, activins bind to cell-surface receptor serine/threonine kinases (RSK) to produce their effects in target cells (Woodruff 1998). Binding to the type II receptors, ACVR2A or ACVR2B, leads to phosphorylation and activation of the type I receptor, ACVR1B (also known as activin receptor-like kinase 4, ALK4). Recent data suggest that a second type I receptor, ACVR1C (ALK7), may also function as an activin $\mathrm{B}$ receptor (Tsuchida et al. 2004). Once activated, both ALK4 and ALK7, which are also RSKs, phosphorylate the intracellular signaling proteins, SMAD2 and SMAD3, on carboxyterminal serine residues. The SMADs then dissociate from the receptor complex, partner with a co-factor (SMAD4) and translocate to the nucleus where they interact with additional co-regulators to stimulate or repress target gene transcription. Although SMADdependent signaling has been most thoroughly characterized, SMAD-independent mechanisms are also important, though these are less well-understood at present and appear to vary between cell types (Attisano \& Wrana 2002, Derynck \& Zhang 2003, Feng \& Derynck 2005).

Whereas activin A can increase $F$ shb mRNA stability (Carroll et al. 1991), the bulk of its effects on expression appears to be mediated via increases in gene transcription. Indeed, activins can stimulate rapid (immediate-early) increases in $F s h b$ subunit transcription in primary rat pituitary cultures (Weiss et al. 1995) and we observed similar effects in the mouse gonadotrope cell line, L $\beta T 2$ (Bernard 2004). In this report, we describe part of the molecular pathway through which activins stimulate this response, using L $\beta$ T2 cells as a model system. The elucidation of this mechanism highlights important species differences in the acute control of FSH synthesis by activins.

\section{Materials and methods}

\section{Reagents and constructs}

Human recombinant (rh-) activin A and follistatin (FST)-288 were purchased from R\&D systems (Minneapolis, MN, USA). Dulbecco's modified Eagle medium (DMEM) with $4.5 \mathrm{~g} / \mathrm{l}$ glucose, L-glutamine and sodium pyruvate was from Mediatech (Herndon, VA, USA). Lipofectamine/Plus, Lipofectamine 2000, and gentamycin were purchased from Invitrogen Fetal bovine serum (FBS) was from JRH Biosciences (Lenexa, KS, USA). The anti-SMAD2 (S-20), anti-SMAD3 (FL-425), and anti-SMAD4 (H-552) rabbit polyclonal antibodies were from Santa Cruz Biotechnologies (Santa Cruz, CA, USA). SMAD2 and phospho-SMAD2 rabbit polyclonal antibodies were from Zymed (South San Francisco, CA, USA) and Cell Signaling Technology (Beverly, MA, USA), respectively. The phosphoSMAD3 rabbit polyclonal antibody was a generous gift of Dr Michael Reiss (Robert Wood Johnson Medical School, New Brunswick, NJ, USA). Protease inhibitor tablets (CompleteMini) were purchased from Roche. Aprotinin, leupeptin, pepstatin and phenylmethylsulphonylfluoride (PMSF) were from Sigma. Deoxynucleotide triphosphates (dNTPs), Taq polymerase, and $5 \times$ Passive Lysis Buffer (PLB) were from Promega (Madison, WI, USA).

The $-1990 /+1 \mathrm{~m} F$ shb-luc reporter, Smad2 and Smad3 short-hairpin RNAs (shRNAs), constitutively active HA-rat ALK4, Flag-human SMAD2, untagged human SMAD3 Flag-human SMAD3, and Flag-mouse Smad4 expression constructs were described previously (Bernard 2004). Myc-SMAD3 and 6xMyc-SMAD4 were from IJ Lebrun (Royal Victoria Hospital, Quebec, Canada) and Ralf Janknecht (Mayo Clinic, Rochester, MN, USA). Flag-human SMAD2 in pCAGGS was a gift of Dr Elizabeth Roberston (Oxford University, UK). Flag-SMAD3-R74K and -K81R were from Dr C H Heldin (The Ludwig Institute, Uppsala, Sweden). Glutathione S-transferase (GST) -SMAD3 MH1 and GST-SMAD4 MH1 were from Dr. Bert Vogelstein (The Johns Hopkins University School of Medicine, MD, USA).

$5^{\prime}$ deletion constructs of the mouse Fshb promoter were made using Erase-a-Base reagents following the manufacturer's instructions (Promega), by PCR or by 
the sub-cloning of restriction fragments from larger reporters. The SBE mutation (GTCTAGAC to GTCatGAC) in $-1990 /+1 \mathrm{~m} F$ shb-luc and the K88R mutation in Flag-mouse Smad4 were produced by site-directed mutagenesis using the QuikChange protocol (Stratagene).

To generate the human FSHB reporter, salivary genomic DNA was extracted from one of the investigators (DJB) using AquaPure reagents (Biorad) and subjected to PCR using PfuUltra Taq (Stratagene, La Jolla, CA, USA) and the following primer set: (forward) 5'-GGCACGGGTGAACTCAATCAGATC ATGTCACGTCACT and (reverse) CGCGTCGAG GAGCTGTAGACTGAATGAAATCTCAGTT. Restriction sites (underlined) were included in the primers to facilitate cloning. The resulting product, corresponding to $-1028 /+7$ of the human FSHB promoter, was digested with $M l u \mathrm{I} / X h o \mathrm{I}$ and ligated into the same sites in pGL3-Basic (Promega) using standard techniques. The 8 base-pair (bp) SBE was introduced into the human promoter using the gene splicing by overlap extension protocol (Horton et al. 1990). Briefly, using the $-1028 /+7$ human reporter as template, two PCRs were performed with the forward primer above and 5'-CTCGAGAGTCTAGACTTTTTCTTTTGTATC TTTAAATCAG and the reverse primer above with 5'-GAAAAAGTCTAGACTGTGGAGTCACAATTAA TTTG. The SBE is underlined and italicized in the splicing primers. The resulting amplicons were pooled and a third round of PCR performed with the forward and reverse primers from above. The resulting amplicon was digested with $M l u \mathrm{I} / X h o \mathrm{I}$ and ligated into the same sites in pGL3-Basic. The identities of all constructs were verified by DNA sequencing.

\section{Cell culture and transfection}

L $\beta$ T2 cells were provided by Dr Pamela Mellon (University of California, San Diego, CA, USA) and were cultured as described previously (Bernard 2004). COS7 cells were obtained from Dr Patricia Morris (Population Council, New York, NY, USA) were cultured in DMEM/10\%FBS. For the majority of transfection experiments, L $\beta$ T2 cells were plated in 24-well plates at a density of $2 \times 10^{5}$ cells per well approximately $36 \mathrm{~h}$ prior to transfection. For SMAD over-expression studies, cells were plated in 6-well dishes at 1.5 to $2 \times 10^{6}$ cells per well. Cells were transfected with Lipofectamine 2000 (24-well) or Lipofectamine/ Plus (6-well) following the manufacturer's instructions. Reporter plasmids were transfected at $450 \mathrm{ng}$ (24-well) or $1 \mu \mathrm{g}$ (6-well) per well. Expression plasmids were introduced at $1 \mu \mathrm{g}$ (6-well) per well. Smad shRNAs were transfected at $100 \mathrm{ng} /$ well at least $24 \mathrm{~h}$ prior to ligand treatment. In all experiments, the total amount of DNA transfected was balanced across treatments. COS7 cells were plated in $10-\mathrm{cm}$ dishes and transfected when $70-100 \%$ confluent with Lipofectamine and the indicated SMAD expression vectors along with ALK4TD.

\section{Reporter assays}

After overnight transfection, L $\beta$ T2 cells were washed in serum-free DMEM and then treated with $1 \mathrm{nM}$ $(25 \mathrm{ng} / \mathrm{ml})$ activin A in DMEM or with DMEM alone (control) for the indicated times. In time-course experiments, the introduction of ligand was staggered so that protein lysates from different treatment groups were collected at the same time. In SMAD over-expression experiments, cells were transfected for $6 \mathrm{~h}$ and then fed with growth media. Lysates were collected the following day for luciferase assays. Cells were washed with $1 \times$ phosphate buffered saline (PBS) and lysed in $1 \times$ PLB. Luciferase assays were performed on a Luminoskan Ascent luminometer (Thermo Labsystems, Franklin, MA, USA) using standard reagents. Luciferase values were normalized by protein concentrations determined for the same samples by bicinchoninic acid assay (Pierce). All treatments were performed in triplicate and the data presented are from 2-3 independent experiments.

\section{Electrophoretic mobility shift assays}

Nuclear extracts were collected and gel shift experiments were performed as described (Therrien \& Drouin 1993), with minor alterations to the protocol. Briefly, following ligand treatment or transfection, cells were washed with $1 \times$ PBS on ice and nuclear extracts collected. Protein concentrations were determined by Bradford assay (BioRad). Nuclear proteins $(3-5 \mu \mathrm{g})$ were incubated at room temperature with $50 \mathrm{fmol}$ of $5^{\prime}{ }^{32} \mathrm{P}-\mathrm{ATP}$ (NEN-PerkinElmer) end-labeled double-stranded probes corresponding to $-277 /-248$ of the mouse Fshb promoter in $25 \mathrm{mM}$ HEPES (pH7.2), $150 \mathrm{mM} \mathrm{KCl}$, $5 \mathrm{mM}$ dithiothreitol, $10 \%$ glycerol and $500 \mathrm{ng}$ salmon sperm DNA at room temperature for $20 \mathrm{~min}$. Reactions were then run on 5\% polyacrylamide gels (44:0.8 acrylamide:bis-acrylamide) in $40 \mathrm{mM}$ Tris- $\mathrm{HCl} /$ $195 \mathrm{mM}$ glycine $(\mathrm{pH} 8.5)$ at 200 volts for $3-5 \mathrm{~h}$ at $4{ }^{\circ} \mathrm{C}$. In competition or antibody super-shift experiments, reactions were assembled at room temperature and incubated for $10 \mathrm{~min}$ with 500 -fold excess unlabeled (cold) competitor or the indicated antibodies prior to the addition of the radio-labeled probe. Gels were dried and exposed to X-ray film.

\section{DNA precipitation}

L $\beta$ T2 cells were plated $\left(1 \times 10^{7}\right)$ in 10 -cm dishes. After three days, cells were washed with serum-free DMEM and incubated overnight in the same. The following day, half of the samples were treated with $60 \mathrm{ng} / \mathrm{ml}$ activin A 
for $1 \mathrm{~h}$. Whole cell lysates were then prepared using $300 \mathrm{mM} \mathrm{NaCl}, 20 \mathrm{mM}$ Tris- $\mathrm{HCl}(\mathrm{pH} 7 \cdot 5), 1 \%$ Triton $\mathrm{X}-100,1 \mathrm{mM}$ PMSF, $2 \mu \mathrm{g} / \mathrm{ml}$ leupeptin and aprotinin. One-tenth of each lysate was then used in a DNA precipitation assay with $100 \mathrm{ng}$ biotinylated mouse Fshb SBE probe following published methods (Choy \& Derynck 2003). Proteins bound to the probe were purified using streptavidin paramagnetic beads (Promega). Following washes, the proteins were eluted from the beads, separated on $10 \%$ NuPage Bis-Tris gels (Invitrogen), transferred to Protran nitrocellulose (Schleicher \& Schuell, Keene, NH, USA), and sequentially probed with rabbit anti-phospho-SMAD2, rabbit anti-phospho-SMAD3, and rabbit anti-SMAD4. The details of the western blotting procedures have been described previously (Bernard 2004).

\section{Statistics}

The data from replicate experiments were highly similar and were pooled ( $n=6$ or 9 per treatment) for statistical analyses. Data are presented as fold-change from the control condition (set to 1) in each experiment. In some cases (where indicated), data were log transformed prior to analysis because of unequal variances between treatments. Differences between means were compared using one- or two-way analyses of variance, followed by post-hoc tests where appropriate (Systat 10.2, Richmond, CA, USA). Significance was assessed relative to $P<0 \cdot 05$.

\section{Results}

\section{Activins stimulate a rapid increase in mouse Fshb promoter activity}

Previously, we showed that activin A stimulates an immediate-early increase in endogenous $F s h b$ transcription in murine LBT2 cells (Bernard 2004). We further showed that a synthetic construct consisting of approximately $2 \mathrm{~kb}$ of the mouse $F s h b 5^{\prime}$ flanking region fused to a luciferase reporter gene $(-1990 /+1 \mathrm{~m} F \mathrm{~s} h b$ luc) was activated by activin $\mathrm{A}$ in cell-restricted fashion (i.e. in L $\beta$ T2 cells, but not in other cell lines; see also (Pernasetti et al. 2001). However, we exposed cells to 20-24 hr of activin A, so it was unclear whether or not the reporter was also acutely (rapidly) regulated. Here, we transfected LBT2 cells with $-1990 /+1 \mathrm{~m} F$ shb-luc and treated them with $1 \mathrm{nM}$ activin $\mathrm{A}$ for varying time periods. Promoter activity increased significantly with time of exposure to activin $\mathrm{A}(P<0.001)$ and differed significantly from control by $4 \mathrm{~h}$ (Fig. 1A). Reporter activity continued to increase through $30 \mathrm{~h}$, the latest time point measured (data not shown). The promoterless vector, pGL3-Basic, was not stimulated by brief activin A treatment (Fig. 1B and data not shown).

\section{Rapid activation of mouse Fshb transcription by activin $A$ requires multiple genetic elements}

To determine cis-regulatory elements mediating the rapid transcriptional response to activin A, L $\beta$ T2 cells were transfected with mouse Fshb promoter-reporter constructs with progressive truncations from the $5^{\prime}$ end and were treated with activin A for $4 \mathrm{~h}$. The results indicated that several promoter regions contributed to the activin A response (Fig. 1B). All of the reporters were stimulated significantly relative to the promoter-less vector (empty), except for $-257 /+1$. Responses increased progressively $5^{\prime}$ of -257 , suggesting that several promoter regions (most proximally between -257 and -398) contributed to rapid transcriptional activation of mouse $F s h b$ by activin A.

\section{Rapid activation of the mouse Fshb promoter is Smad-dependent}

In other systems, SMAD proteins often broker the rapid actions of activins and TGFBs on transcription through direct DNA binding of SMAD3 and/or SMAD4 to target gene promoters (Yang et al. 2003, Levy \& Hill 2005). We observed previously that Smad2 and Smad3 were rapidly phosphorylated and trans-located to the nucleus upon activin A treatment (within 5-10 min) (Bernard 2004), a time frame consistent with their potential roles in immediate-early gene activation. To determine the functional relevance of these proteins, we suppressed endogenous Smad2 or Smad3 protein levels in L $\beta$ T2 cells by RNA interference (RNAi) using previously validated shRNAs (Bernard 2004). Cells were co-transfected with Smad2 or Smad3 shRNA constructs or empty vector (pBS/U6) and $-1990 /+1 \mathrm{~m} F$ shb-luc, and were treated with activin A for 4,8 or $24 \mathrm{~h}$. As reported previously, both shRNAs inhibited the effects of $24 \mathrm{~h}$ activin A (Figs. 2 A, B) (Bernard 2004). Here, we also observed significant antagonism of the activin A responses at 4 and $8 \mathrm{~h}$. Importantly, when correcting for the small (though non-significant) declines in baseline activity, suppression of Smad2 or Smad3 protein levels inhibited activin A-stimulated reporter activity at all time points by $23-27 \%$ or $25-43 \%$ respectively.

\section{The consensus SBE at $-266 /-259$ can bind endogenous SMADs in an activin A-stimulated manner}

We screened the activin A-sensitive promoter regions for potential SMAD binding elements (SBE) and observed a perfect 8-bp palindromic element, 5'-GTCTAGAC-3' (Zawel et al. 1998), located at -266/ - 259 (see Fig. 8A), within the $-398 /-257$ interval (Fig. 1B). This element consists of tandem SMAD boxes, 5'-GTCT-3', in inverted-repeat orientation. To determine whether 

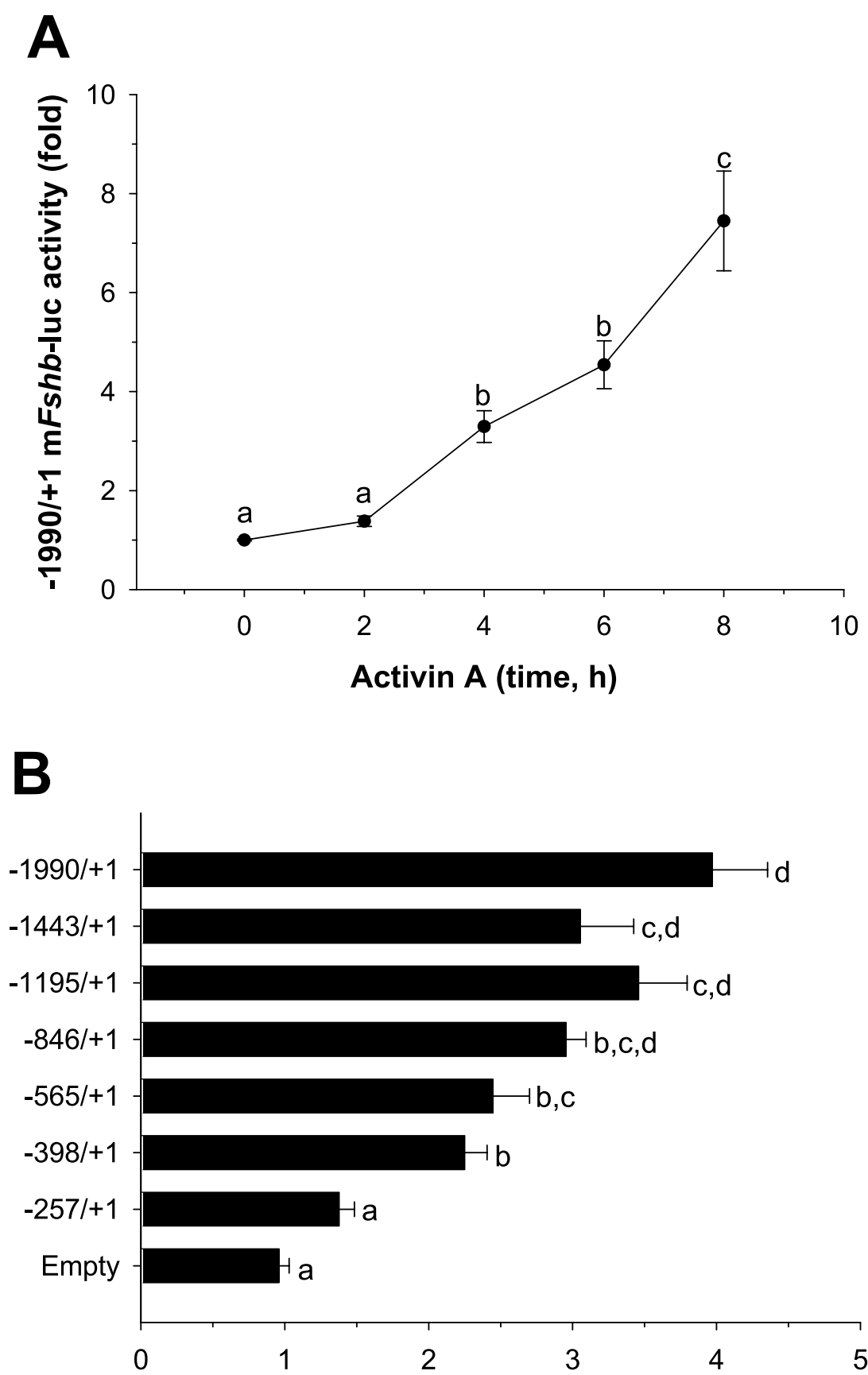

Fold stimulation by $4 \mathrm{~h}$ activin $A$

Figure 1 Activin A stimulates rapid activation of the mouse Fshb promoter through multiple cis-elements. (A) L $\beta$ T2 cells were transfected with $-1990 /+1 \mathrm{~m} F$ shb-luc and were treated with $1 \mathrm{nM}$ activin A for the indicated periods of time. Data reflect fold-stimulation of luciferase activity relative to untreated control cells (time 0). Data are from two experiments performed in triplicate and are means +/- S.E.M. Points with different letters differed significantly (Bonferroni). (B) L $\beta$ T2 cells were transfected with the indicated mouse Fshb promoter-reporter constructs and treated with $1 \mathrm{nM}$ activin A for $4 \mathrm{~h}$. The values represent fold-stimulation of luciferase activity by activin A. Due to the differences in basal promoter activity with the different constructs, data were normalized to untreated cells with the same reporter. Data were derived from three experiments performed in triplicate and were log transformed prior to analysis. Bars reflect means and errors are S.E.M. Bars with different letters differed significantly (Bonferroni). 

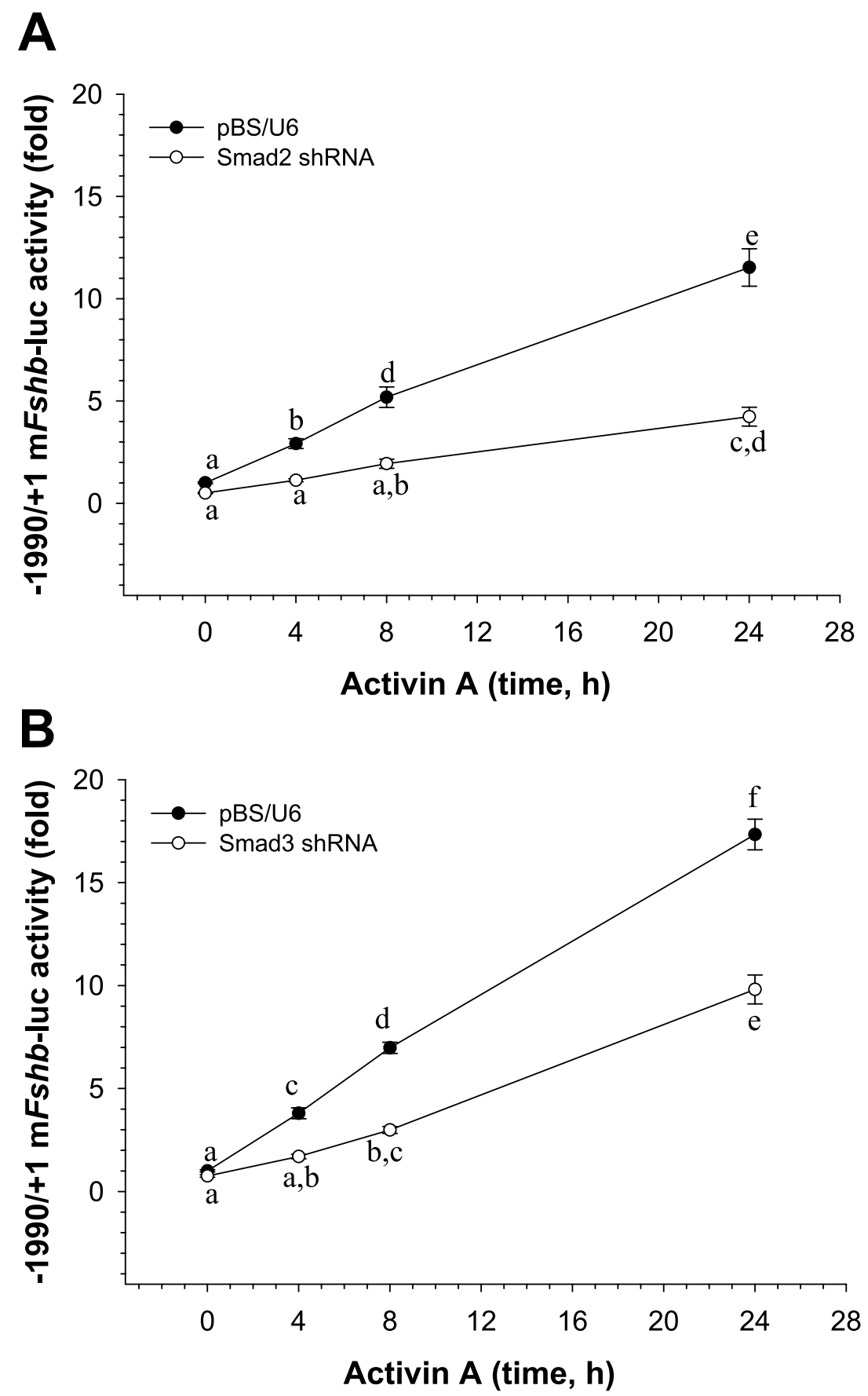

Figure 2 Activin A stimulates rapid activation of the mouse Fshb promoter through a Smad2/3-dependent mechanism. (A) L $\beta T 2$ cells were co-transfected

$-1990 /+1 \mathrm{~m} F$ shb-luc and $100 \mathrm{ng} /$ well pBS/U6 or pBS/U6-Smad2 shRNA. Cells were treated with $1 \mathrm{nM}$ activin $A$ for 4,8 or $24 \mathrm{~h}$. Data reflect changes in luciferase activity and are plotted relative to the untreated pBS/U6 condition. (B) L $\beta T 2$ cells were transfected and activin A treated as described in A, except pBS/U6-Smad3 shRNA was used in place of pBS/U6-Smad2 shRNA. In both panels, means and S.E.M. were derived from three experiments performed in triplicate. Points with different letters differed significantly from one another (Bonferroni of significant interactions). 
Smads in L $\beta$ T2 cells might exert their actions through this element, we first confirmed direct protein binding by gel shift analyses. SMADs 3 and 4, but not SMAD2, bind SBEs through their amino-terminal Mad homology 1 (MH1) domains (Shi et al. 1998, Zawel et al. 1998). We used human GST-SMAD3 MH1 and GSTSMAD4 MH1 fusion proteins and incubated them with a radio-labeled probe corresponding to $-277 /-248$ of the mouse $F s h b$ promoter (hereafter $\mathrm{m} F$ sh $b \mathrm{SBE}$ probe). As predicted, both recombinant proteins interacted directly with the probe (Fig. 3A, lanes $1-3$ and 6-8). The abundance of the complexes increased as more recombinant protein was inputted into the assay. In both cases, complexes were disrupted by 500-fold excess unlabeled homologous competitor probe (lanes 4 and 9) and were super-shifted by SMAD-specific antibodies (lanes 5 and 10), confirming that the interactions were specific and that the indicated SMAD proteins were contained within the observed complexes. GST alone did not interact with the $\mathrm{m} F$ shb SBE probe (data not shown).

We next examined whether activin A stimulated the formation endogenous Smad complexes in L $\beta$ T2 cells that could interact with the SBE. Using gel shift analyses with nuclear extracts from control and activin A-treated cells and the mFshb SBE probe, we detected five DNA/protein complexes (labeled a-e from top to bottom, compare lanes 1 and 4; only complexes a-c are presented) (Fig. 3B). Complexes b-e, but not a, were specific and could be competed by incubation with 500-fold excess unlabeled probe lane 5 and data not shown). One hour of activin A treatment stimulated an increase in the abundance of complexes b and c (lane 4, compare with control cells in lane 2). In addition, overnight incubation of cells with the activin antagonist FST-288 decreased the abundance of these two, but not the other, complexes (lane 3), consistent with previous observations that there is low level endogenous activin (probably activin B) signaling in these cells (Pernasetti et al. 2001). Increased complex abundance could be detected at 30 min post-activin A treatment, peaked at 2-3 $\mathrm{h}$ and returned to baseline levels by $24 \mathrm{~h}$ (data not shown).

To determine whether or not complexes b and c contained Smads, super-shift experiments were performed with SMAD-specific antibodies (Fig. 3B). Control IgG and anti-SMAD1 (a BMP-regulated SMAD) had no effects on either complex b or c (lanes 6 and 7). In contrast, an anti-SMAD2 antibody disrupted the formation of complex b (lane 8), whereas antiSMAD3 (lane 9) and anti-SMAD4 (lane 10) antibodies caused super-shifts of both complexes b and c.

To further demonstrate the presence of the indicated Smads in complexes b and c, we over-expressed human SMADs 2 and 3, and mouse Smad4 alone and in combination in heterologous COS7 cells and used nuclear extracts in gel shift analyses with the mFshb SBE probe (Fig. 3B). A complex with similar mobility as complex c in L $\beta$ T2 cell lysates was detected in control cells transfected with a constitutively active form of the activin type IB receptor (ALK4TD), which generates ligand-like signals in the absence of exogenous ligand (lane 11) (Attisano et al. 1996). Super-shift experiments indicated the presence of endogenous SMAD3 and SMAD4 in this complex (data not shown). Transfection of SMAD2 or Smad4 alone did not significantly alter complex formation (data not shown), whereas the abundance of the complex increased markedly in cells co-transfected with SMAD3 (data not shown, but see Fig. 6). This complex also appeared to include endogenous SMAD4, as it was super-shifted by an anti-SMAD4 antibody (data not shown). The abundance of the complex was further enhanced upon cotransfection of SMADs 3 and 4 (lane 13). Whereas the combination of SMAD2 and Smad4 had no detectable impact on complex formation (lane 12), when the three proteins were co-expressed there was a significant increase in the abundance of two complexes with similar mobility to those of complexes b and c from L $\beta$ T2 cells (lane 14). An anti-SMAD2 antibody disrupted the formation of complex b from COS7 cells (Fig. 3C, lane 2) and anti-SMAD3 and 4 antibodies super-shifted both complexes (Fig. 3C, lanes 3 and 4). These data were consistent with the observations from L $\beta$ T2 cells that protein complexes containing Smads 2, 3 and 4 can interact with the SBE at -266/ - 259 in activin/ALK4regulated fashion.

To confirm that activin A stimulated the formation of endogenous Smad2/3/4 complexes that could bind the SBE, we performed DNA precipitation assays (Choy \& Derynck 2003). Using a biotinylated $\mathrm{m} F$ shb SBE probe, we precipitated protein complexes from control and activin A-stimulated L 3 T2 cell lysates and subjected them to western blot analyses using phospho (p)-SMAD2 and pSMAD3 specific antibodies. Activin A stimulated increases in pSMAD2 and pSMAD3 levels and these proteins could interact with the $\mathrm{m} F$ shb $\mathrm{SBE}$ probe (Fig. $3 \mathrm{D}$, top two panels). The pSMAD2 antibody detected two proteins in this assay. The smaller of the two likely corresponded to the SMAD2 splice variant, SMAD2 $\Delta$ exon3, which we showed previously was expressed in L $\beta$ T2 cells and could stimulate endogenous mouse Fshb expression (Bernard 2004). Importantly, the amount of Smad4 associating with the biotinylated SBE probe was also increased by activin A (third panel from the top), despite the fact that the total amount of Smad4 in the cell lysates was equivalent in the different treatment conditions (Fig. 3D, bottom panel).

Collectively, the gel shift and DNA precipitation data show that activin A stimulated the formation of at least two complexes that could interact with the SBE at -266/ - 259, one containing pSmad2, pSmad3, and 
A

\section{GST-SMAD3MH1 GST-SMAD4MH1}

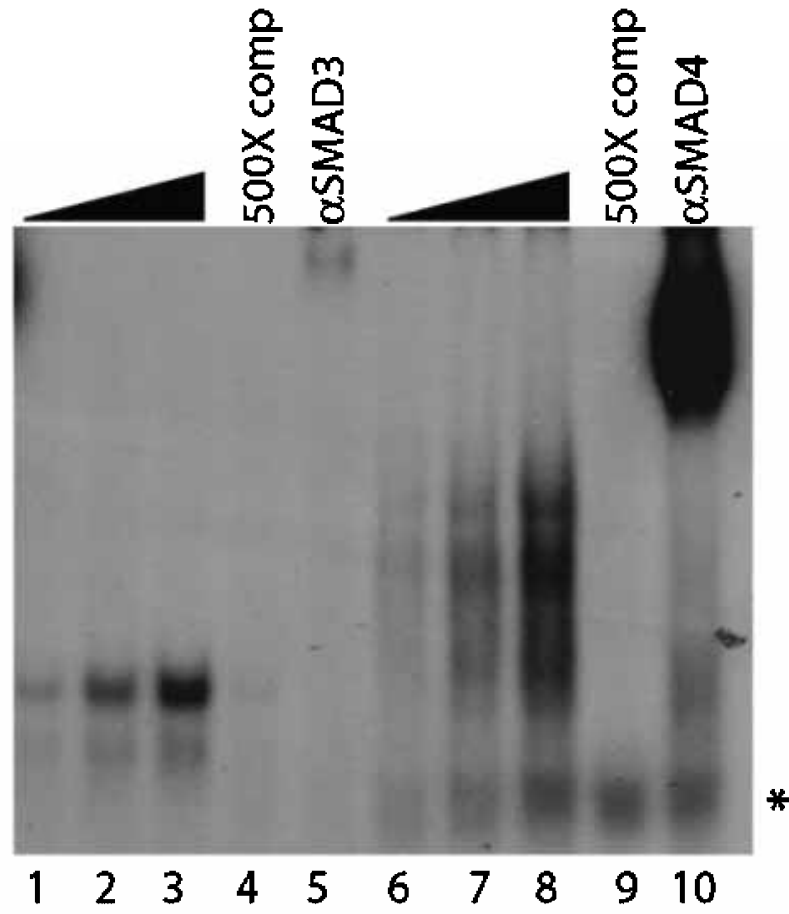

D

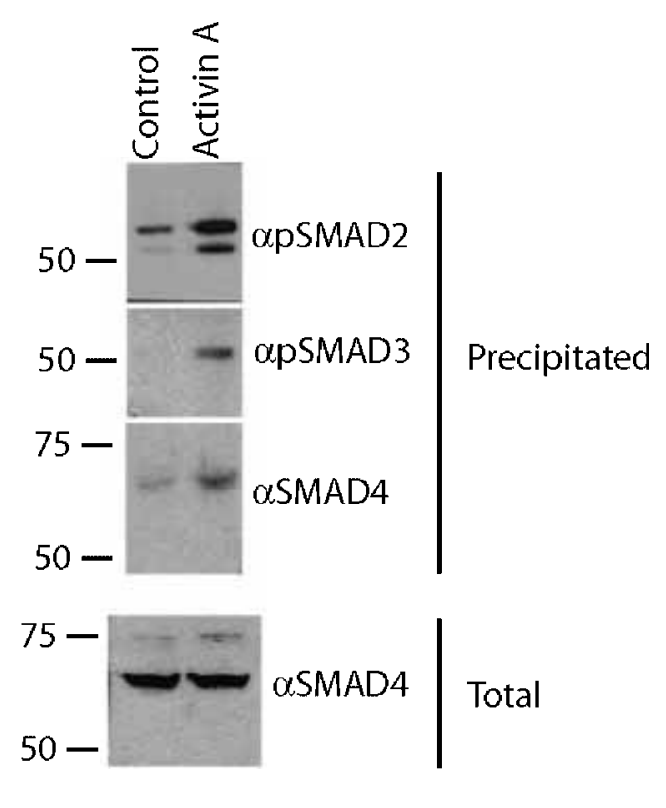

B

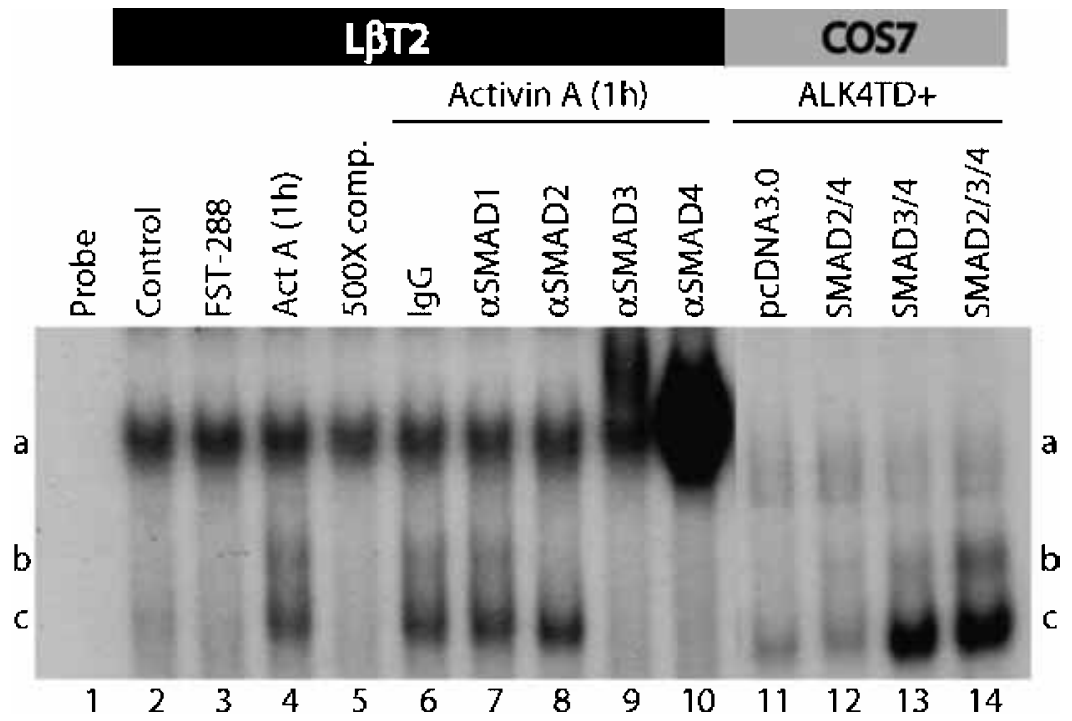

C

ALK4TD + SMAD2/3/4

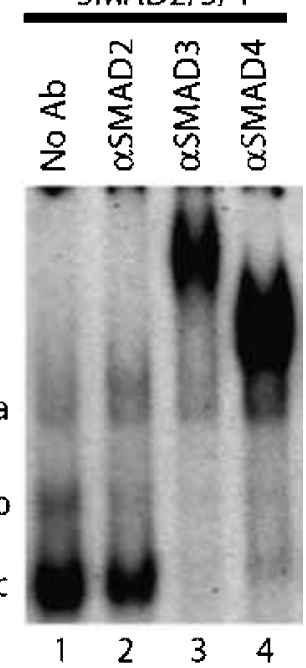


Smad4 (complex b) and the other containing pSmad3 and Smad4 (complex c).

\section{SMADs 2, 3 and 4 synergistically stimulate Fshb transcription}

In many systems, over-expression of receptor-regulated (R-) SMADs, like SMADs 2 and 3, can produce effects similar to those of the ligands that activate them, indirectly implicating their functional roles in the underlying signaling pathway (Zhang et al. 1996, Nakao et al. 1997). We employed this approach here to probe the involvement of Smads 2, 3 and 4 in mouse Fshb transcription. To overcome previous difficulties in over-expressing SMAD2 in L $\beta$ T2 cells (Bernard 2004, Gregory et al. 2005), while avoiding a need to change our culturing conditions (Suszko et al. 2005), we used Flag-tagged full-length human SMAD2 in pCAGGS (Dunn et al. 2004), which contains the chicken $\beta$-actin promoter (Niwa et al. 1991). Using this construct we were able to over-express full-length SMAD2 in L $\beta$ T2 cells at levels comparable to over-expressed SMAD3 from the weaker CMV promoter (Fig. 4A). As before, exogenous full-length SMAD2 expression from the CMV promoter was comparatively low (compare lanes 2 and 3 to lane 4 ).

Using this new vector, we co-transfected L $\beta$ T2 cells with $-1990 /+1 \mathrm{~m} F$ shb-luc and different combinations of human SMADs 2, 3 and 4. As seen previously in rat (Suszko et al. 2003, 2005, Gregory et al. 2005), SMAD3 alone and in combination with SMAD4 stimulated mouse Fshb reporter activity (Fig. 4B). SMAD2 alone had no effect, but with SMAD4 was as potent as SMAD3 alone. Remarkably, the combination of SMADs 2, 3 and 4 had very potent transcriptional activity and stimulated the reporter 3 to 5-fold more strongly than SMADs 3 and 4 together. In addition, the combination of SMAD2/3 was as potent as SMAD3/4. These novel data further implicated endogenous Smad2 in transcriptional regulation of the mouse Fshb gene.

\section{The SBE is required for activin A- and SMAD2/3/4-stimulated Fshb transcription}

We next examined the functional relevance of the SBE for rapid effects of activin A on mouse $F$ shb transcription. Previous studies showed that a mutation of $2 \mathrm{bp}$ in the center of the SBE of the human SMAD7 promoter, 5'-GTCTAGAC-3' to 5'-GTCatGAC-3', abolished TGFB1-stimulated promoter activity (von Gersdorff et al. 2000). We therefore examined the effects of this 2-bp mutation in the context of the mouse $F$ shb SBE. Using a radiolabeled wild-type $\mathrm{m} F$ shb $\mathrm{SBE}$ probe in gel shift analyses, we observed that activin A stimulated the formation of complexes b and $\mathrm{c}$ as described earlier (Fig. 5A, compare lanes 2 and 3). A 500-fold molar excess of unlabeled wild-type (WT) probe completely blocked complex formation (lane 4), whereas a competitor probe with the 2-bp mutation (Mut) at positions 4 and 5 of the 8-bp SBE did not (lane 5). Thus, these bp were required for Smad complex binding to the mouse Fshb promoter just as in the SMAD7 promoter.

We next introduced the 2-bp mutation in the SBE into the $-1990 /+1 \mathrm{~m} F$ shb-luc reporter. L $\beta$ T2 cells were transfected with wild-type and SBE mutated constructs (SBEmut) and treated with activin A for 4,8 or $24 \mathrm{~h}$. The mutation did not significantly affect baseline reporter activity in these experiments, but impaired the stimulatory effects of activin A at all time points (Fig. 5B). This was particularly true at 4 and $8 \mathrm{~h}$, where activin A failed to significantly stimulate reporter activity from the SBEmut construct. By $24 \mathrm{~h}$, activin A stimulated the mutated promoter, though to a lesser extent than observed with wild-type at 8 or $24 \mathrm{~h}$. Importantly, the same mutation almost completely inhibited the effects of $\mathrm{SMAD} 2 / 3, \quad \mathrm{SMAD} 3 / 4$ and SMAD2/3/4 overexpression on mouse Fshb transcription (Fig. 5C).

\section{Both SMAD3 and SMAD4 must bind to the SBE for maximal transcriptional activation}

We next hypothesized that within the Smad complexes described above, both Smad3 and Smad4 bound to the

Figure 3 Activin A stimulates the formation of Smad2/3/4 complexes that bind the SBE at $-266 /-259$. (A) Gel shift analyses were performed with a radiolabeled probe corresponding to $-277 /-248$ of the mouse Fshb promoter. The probe was incubated with approximately 50 (lanes 1 and 6), 100 (lanes 2 and 7), or $200 \mathrm{ng}$ (lanes 3-5 and 8-10) of the indicated recombinant GST fusion proteins. Five hundred fold unlabeled homologous probe was included to assess specificity of binding (lanes 4 and 9 ). The asterisk denotes non-specific binding in the presence of the GST-SMAD4 MH1 protein. SMAD3 (lane 5) and SMAD4 (lane 10) antibodies were included to confirm that complexes contained the indicated SMAD proteins. (B) Gel shift analyses were performed with the probe described in $A$ and nuclear extracts purified from L $\beta$ T2 (lanes 2-10) or transfected COS7 cells (lanes 11-14). Three of five complexes detected in L $\beta$ T2 cell lysates are labeled at the left (a-c). For competition (lane 5) and antibody super-shift analyses (lanes 6-10), nuclear extracts from activin A-treated L $\beta$ T2 cells (lane 4) were used. In lanes 11-14, nuclear extracts from COS7 cells transfected with ALK4TD and the indicated SMAD expression constructs were subjected to gel shift analyses with the $-277 /-248$ probe. Complexes with similar mobility to those from L $\beta$ T2 cell lysates are labeled at the right. (C) Nuclear extracts from COS7 cells transfected with human SMADs 2 and 3, and mouse Smad4 were subjected to gel shift analysis as described in B. The indicated antibodies were added to samples in lanes 2-4. In panels A-C, free (unbound probe) is not pictured and lanes are numbered at the bottom. (D) Using a biotinylated $\mathrm{mFshb}$ SBE probe, proteins from control L $\beta$ T2 cells or cells treated with activin A for $1 \mathrm{~h}$ were precipitated with streptavidin paramagnetic beads. Eluted proteins were resolved by SDS-PAGE, transferred to nitrocellulose and consecutively blotted with the indicated antibodies. Whole cell lysates prior to precipitation (total) were also probed for SMAD4 to show that equivalent concentrations of proteins were used in the two treatment groups (bottom panel). 
A

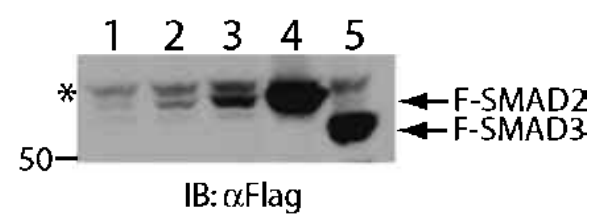

B

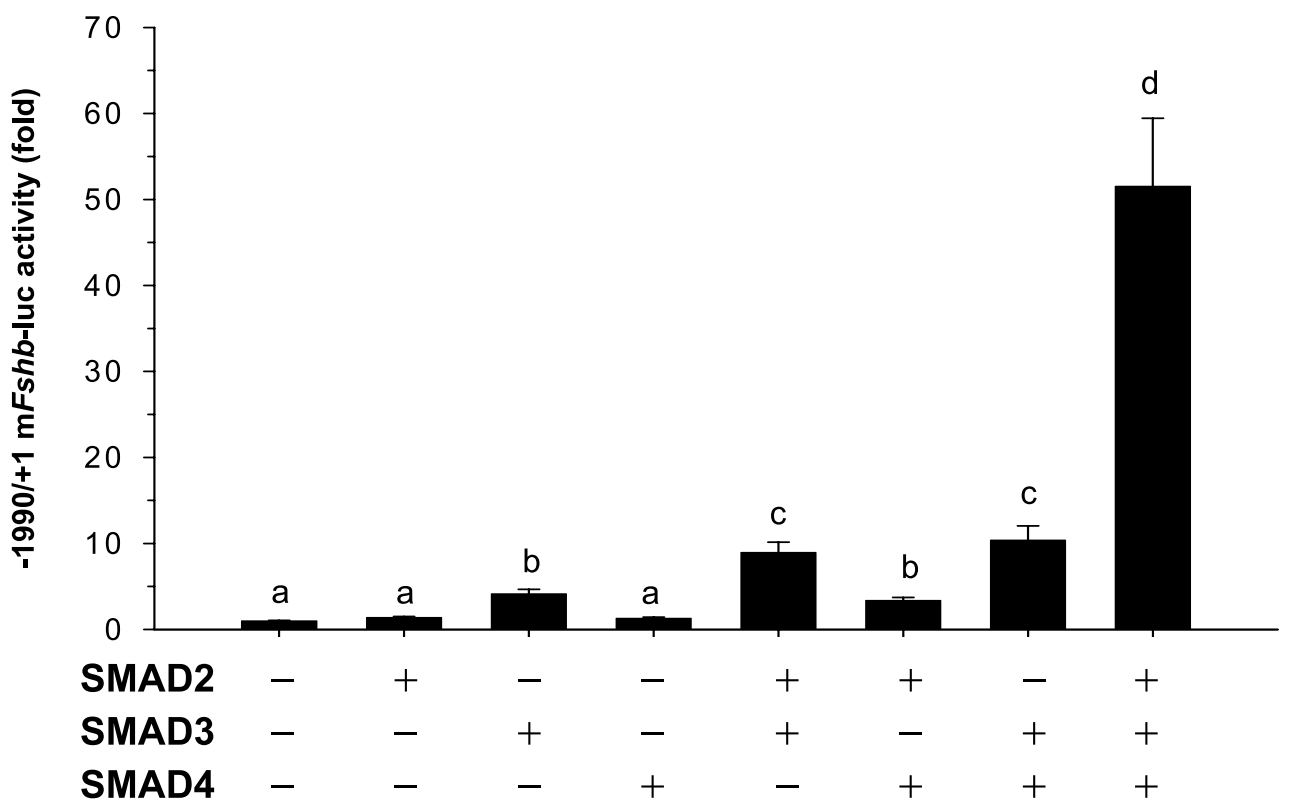

Figure 4 Over-expression of SMAD2/3/4 potently stimulates mouse Fshb promoter activity in L $\beta$ T2 cells. (A) $L \beta T 2$ cells were plated in 6 -well plates and grown to near confluence. Cells were transfected with $2 \mu \mathrm{g} /$ well with the following constructs: 1) pcDNA3.0, 2) human Flag-SMAD2 in pcDNA3.0, 3) human Flag-SMAD2 in pCMV5, 4) human Flag-SMAD2 in pCAGGS, or 5) human Flag-SMAD3 in pCMV5B. After $24 \mathrm{~h}$, whole cell protein lysates were collected and subjected to western blot analysis with a Flag antibody. The asterisk indicates a non-specific band. (B) L $\beta T 2$ cells were co-transfected with $-1990 /+1 \mathrm{mFshb}$-luc and the indicated SMAD expression constructs for approximately $24 \mathrm{~h}$. The bars reflect mean (+/- S.E.M.) increases in luciferase activity and are normalized relative to the pcDNA3.0 condition. Data were derived from three experiments performed in triplicate and analyses were performed on log transformed data. Bars with different letters differ significantly (Bonferroni).

tandem SBE simultaneously, with each binding to one of the two SMAD boxes (Shi et al. 1998, Chai et al. 2003). We focused on these two Smads because they were present in both complexes b and c in gel-shift analyses (Fig. 3) and because full-length SMAD2 cannot bind SBEs directly owing to a 30 amino acid insertion in its MH1 domain (Dennler et al. 1999, Yagi et al. 1999). If this hypothesis was correct, then disruption of either Smad3 or Smad4 binding should destabilize the protein-DNA interaction and attenuate transcriptional activation. Consistent with this proposition, mutations to single bp within one SMAD box or the other inhibited endogenous Smad complex binding to the SBE (data not shown). To complement these observations, we examined the effects of point mutations in the MH1 $\beta$-hairpins of SMAD3 and SMAD4 on DNA binding and trans-activation of the mouse Fshb promoter.

Conservative substitutions at R74 (R74K) and K81 $(\mathrm{K} 81 \mathrm{R})$ in the $\beta$-hairpin of the $\mathrm{MH} 1$ domain were shown previously to inhibit SMAD3-mediated transcriptional activation presumably by disrupting DNA binding, though this was not shown directly (Moren et al. 2000). To confirm that that these mutations indeed disrupt binding, we co-transfected COS7 cells with 
wild-type (WT) SMAD3, SMAD3-R74K, or SMAD3K81R alone or in combination with wild-type Smad4. ALK4TD and SMAD2 were co-transfected in all cases. Nuclear extracts were subjected to gel shift analyses with the $\mathrm{m} F$ shb SBE probe. SMAD3-WT alone and in combination with Smad4 formed a complex with the DNA probe (Fig. 6, lanes 2 and 5). We could not detect binding of either SMAD3 mutant to the SBE probe when over-expressed alone or with Smad4 (lanes 3, 4, 6, and 7), suggesting that both mutations impaired binding to the SBE. Western blots of the nuclear extracts used in the gel shift analysis indicated comparable levels of pSMAD3 in the different conditions (Fig. 6, bottom panel).

A

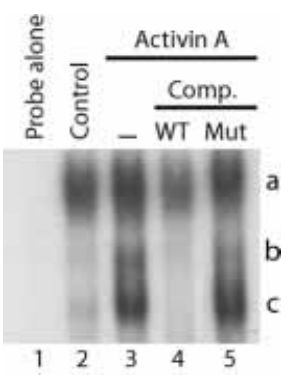

B

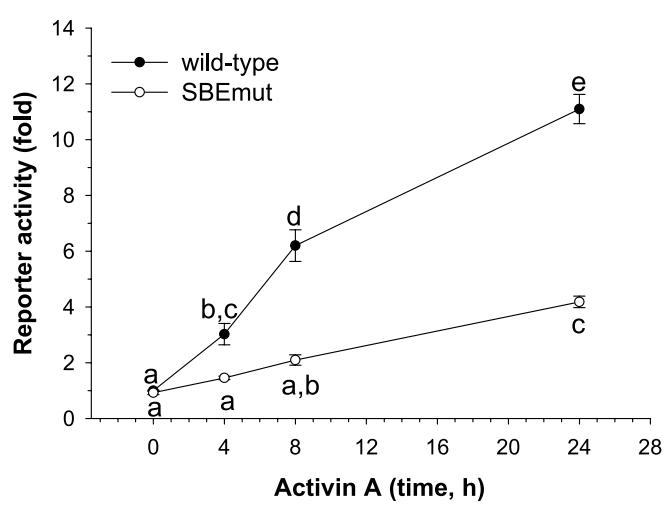

C

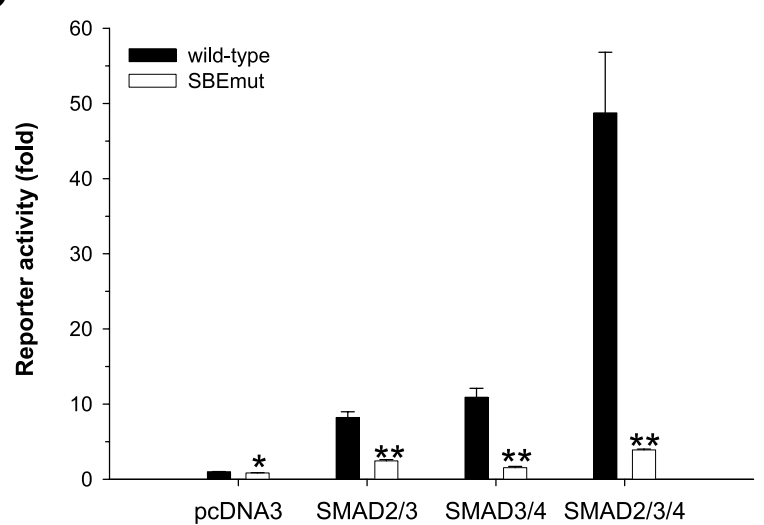

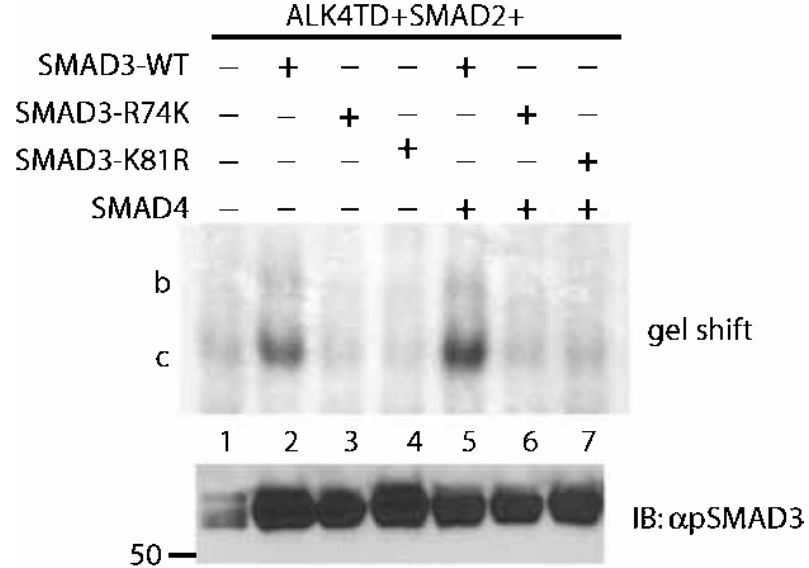

Figure 6 SMAD3-R74K and -K81R fail to bind the SBE at $-266 /-259$. (A) Nuclear extracts from COS7 cells transfected with ALK4TD and SMAD2 along with the indicated forms of SMAD3 with or without Smad4 were subjected to gel shift analyses with the $\mathrm{mFshb}$ probe as described in Fig. 3 . Complexes with similar mobility to those of complexes b and $c$ in Fig. 3B are labeled at the left. Free probe is not presented. The bottom panel shows an anti-pSMAD3 western blot of the nuclear extracts used in the top panel.

We next examined the functional consequences of these mutations in SMAD3. Wild-type SMAD3, SMAD3-R74K, and SMAD3-K81R were overexpressed alone and in combination with Smad4 in L $\beta$ T2 cells along with the $-1990 /+1 \mathrm{~m} F$ shb-luc reporter.

Figure 5 Mutation of the SBE in the proximal mouse Fshb promoter impairs activin A and SMAD-dependent trans-activation. (A) A gel shift analysis was performed with the $\mathrm{m} F$ shb probe and nuclear extracts from control (lane 2) or activin A-treated $(1 \mathrm{~h}) \mathrm{L} \beta \mathrm{T} 2$ cells (lanes $3-5)$. An unlabeled wild-type (WT) or a mutated (Mut) competitor probe with point mutations at position 4 and 5 of the 8 -bp SBE were added at 500-fold molar excess concentration (lanes 4 and 5). The complexes are labeled at the right consistent with their original description in Fig. 3B. (B) L $\beta T 2$ cells seeded in 24-well plates were transfected with $-1990 /+1 \mathrm{~m} F$ shb-luc (wild-type, filled circles) or $-1990 /+1 \mathrm{~m} F$ shb SBEmut-luc (SBEmut, open circles). Cells were treated in serum-free DMEM in the presence or absence of $1 \mathrm{nM}$ activin $A$ for the indicated times. The points reflect mean (+/-S.E.M.) fold-changes in luciferase activity normalized to the untreated wild-type reporter. The data were derived from two experiments, with each treatment performed in triplicate. Points with different letters differed significantly (Bonferroni post-hoc test of significant interaction). (C) L $\beta T 2$ cells seeded in 6-well plates were transfected with wild-type (filled bars) or SBEmut (open bars) mouse Fshb reporters and the indicated combinations of SMAD expression constructs. After approximately $24 \mathrm{~h}$, lysates were collected for luciferase assays. The bars reflect mean (+/-S.E.M.) fold-changes in luciferase activity normalized to the wild-type reporter transfected with empty vector, pcDNA3.0. The presented data were derived from two experiments, with each treatment performed in triplicate. Asterisks indicate statistically significant differences between the wild-type and SBE mutant promoters (t-tests), ${ }^{*} P<0.02,{ }^{\star *} P<0.005$. 
Wild-type SMAD3 stimulated transcription and Smad4 potentiated this effect (Fig. 7A). Neither SMAD3 mutant when expressed alone significantly stimulated reporter activity (Fig. 7A) even though the various forms of SMAD3 were over-expressed at comparable levels (data not shown). Co-expression of Smad4, which had no effect on its own, partially rescued the effect of SMAD3-R74K to approximately 50\% of the level seen with wild-type SMAD3/Smad4 and to a level comparable with wild-type SMAD3 expressed alone. There was a trend for Smad4 to partially rescue the effects of SMAD3-K81R, but the fold-stimulation was not as great as wild-type SMAD3 alone or the SMAD3-R74K/Smad4 combination. Stimulation of cells with activin A for approximately $24 \mathrm{~h}$ increased transcriptional activation in all cases but did not alter the functional differences seen between the SMAD3 variants (data not shown). Note that the overall level of trans-activation was greater in these experiments than in those described above (Fig. 4B and 5C) likely because the analyses here were in cells from an earlier passage and because less DNA overall was transfected here.

A point mutation in the MH1 $\beta$-hairpin of SMAD4, SMAD4-K88R (equivalent to K81R in SMAD3), was shown previously to disrupt both DNA binding and trans-activation function (Moren et al. 2000). We overexpressed this form of the mouse protein in L $\beta T 2$ cells with the $-1990 /+1 \mathrm{~m} F$ shb-luc reporter. Like wild-type (WT) Smad4, Smad4-K88R alone failed to stimulate promoter activity (Fig. 7B). However, whereas WTSmad4 potentiated the effect of over-expressed SMAD3, Smad4-K88R was unable to do so significantly. Further, we observed that Smad4 could partially rescue the trans-activation by SMAD3-R74K (Fig. 7A). We postulated that Smad4 accomplished this by providing some DNA binding ability to the complex, even though it is of reduced affinity relative to complexes with wild-type proteins. Indeed, Smad4-K88R was unable to rescue transcriptional activation by SMAD3-R74K (Fig. 7B). Collectively, the data suggest that both SMADs 3 and 4 must bind directly and simultaneously to the SBE to maximally stimulate mouse $F$ shb promoter activity.

\section{Inter-species differences activin/SMAD activation of Fshb transcription}

Finally, we examined whether the mechanisms observed in mice extended to humans. We cloned approximately $1 \mathrm{~kb}$ of the human proximal FSHB promoter and compared the nucleotide sequence with that of mouse. The two promoters were highly similar within the first $\sim 330-340$ bp (>72\% identity, including gaps) of their respective transcription start sites, but diverged thereafter (Fig. 8A). Interestingly, within the conserved proximal region, an 8-bp gap had to be introduced into the human sequence to facilitate the alignment between the two species and this occurred at exactly the position of the SBE in mouse (Fig. 8A, boxed sequence). Due to the important role of this element in the acute and overall sensitivity of the mouse promoter to activin A (Fig. 5), we hypothesized that the human FSHB promoter might display different activin-response properties. We transfected LBT2 cells with $-1028 /+7 \mathrm{~h} F S H B$-luc or a mouse reporter of similar length, $-1195 /+1 \mathrm{~m} F$ shb-luc, and treated them with activin A for 4,8 or $24 \mathrm{~h}$. Mouse $-1195 /+1 \mathrm{~m} F$ shb-luc was stimulated by activin A at all time points (Fig. 8B). In contrast, the human reporter was only significantly up-regulated between $8-24 \mathrm{~h}$. The fold-stimulation observed at $24 \mathrm{~h}$ activin $\mathrm{A}$ was significantly greater than that observed with the promoter-less vector, pGL3-Basic (data not shown), showing that activin A regulation did depend upon sequences within the human promoter.

To determine whether the lack of the SBE in the human promoter might contribute to its lesser sensitivity to activins, we introduced the 8-bp element into the human reporter (hereafter $-1028 /+7 \mathrm{~h} F S H B(\mathrm{SBE}+$ )-luc in the location of the gap pictured in Fig. 8A, between bps -276 and -275 . Unlike the wild-type promoter, $-1028 /+7 \mathrm{~h} F S H B(\mathrm{SBE}+)-$ luc responded to activin A within $4 \mathrm{~h}$ and was stimulated to a greater extent at $24 \mathrm{~h}$. However, even with this modification, the human promoter was still not as sensitive to activin $\mathrm{A}$ as the mouse promoter either acutely $(4-8 \mathrm{~h})$ or chronically $(24 \mathrm{~h})$. We then compared the sensitivity of the mouse and human promoters to SMAD2/3/4 over-expression. Whereas $-1195 /+1 \mathrm{~m} F$ shb-luc was significantly stimulated by SMADs, the wild-type human promoter was not (Fig. 8C). Addition of the SBE to the human promoter conferred SMAD responsiveness, but as with activin A treatment, the overall level of activation was not elevated to that seen in mouse (Fig. 8C).

To determine whether or not the persistent differences between $-1195 /+1 \mathrm{~m} F$ shb-luc and $-1028 /$ $+7 \mathrm{~h} F$ shb $(\mathrm{SBE}+)$-luc were at least partly attributable to elements upstream of the SBE, we examined the activin A response properties of a truncated mouse promoter $(-269 /+1 \mathrm{~m} F$ shb-luc $)$, which contained the SBE and proximal promoter, but lacked more distal elements. This reporter responded to activin A and SMAD2/3/4 more similarly to $-1028 /+7 \mathrm{~h} F S H B(\mathrm{SBE}+)$-luc than to $-1195 /+1 \mathrm{~m} F$ shb-luc (Figs. 8B and C), suggesting that elements distal to the SBE, which are divergent between mouse and human, contribute to responsiveness of the mouse promoter to activins and SMADs, and this was consistent with results from the $5^{\prime}$ deletion experiments (Fig. 1B).

\section{Discussion}

Activins rapidly stimulate $F_{s} h b$ subunit transcription in mice and rats (Weiss et al. 1995, Bernard 2004). Here, 
A

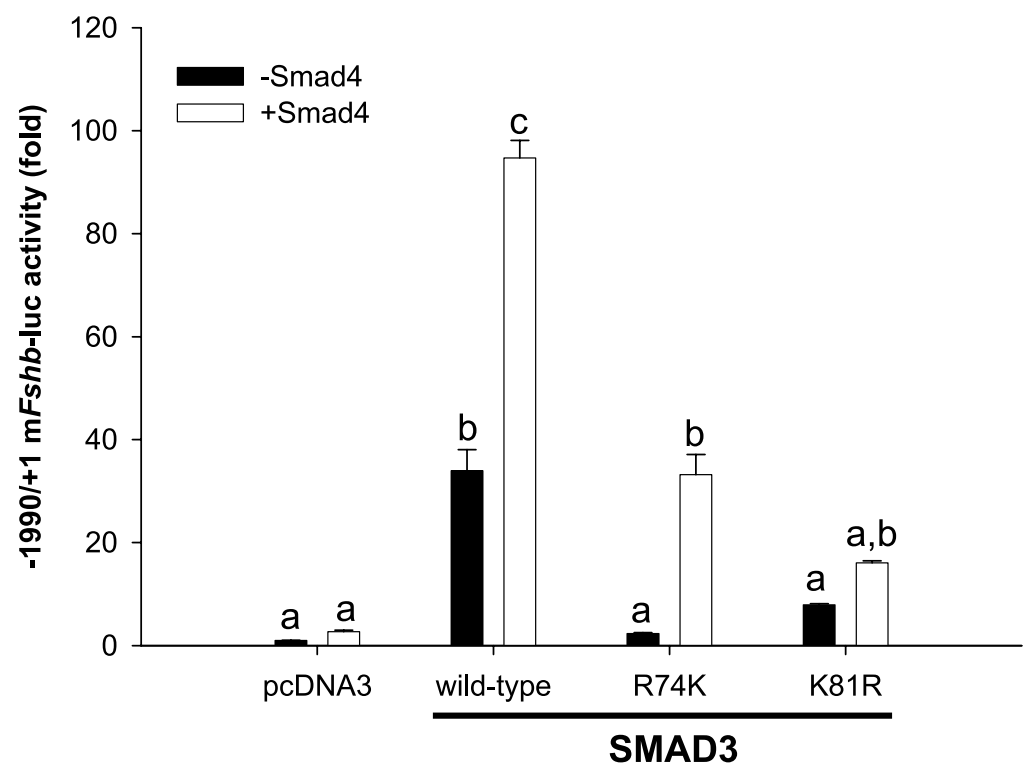

B

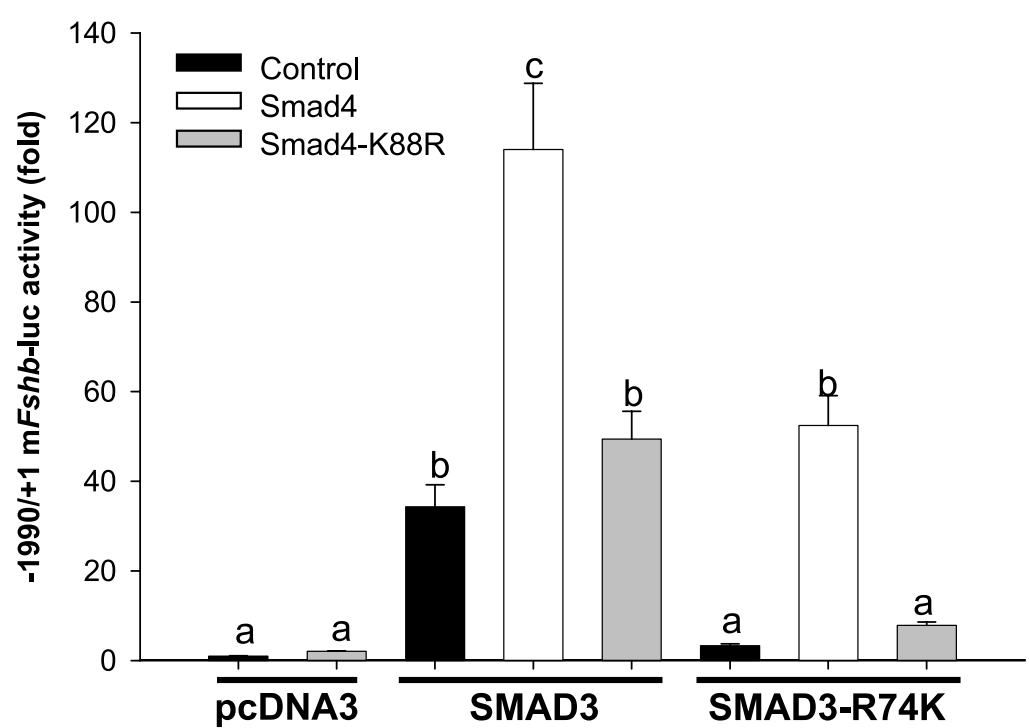

Figure 7 DNA binding-deficient forms of SMAD3 and Smad4 have reduced transcriptional activation function. (A) L $\beta T 2$ cells were transfected with the $-1990 /+1 \mathrm{~m}$ Fshb-luc reporter and empty expression vector (pcDNA3), wild-type SMAD3, SMAD3-R74K, or SMAD3-K81R alone (black bars) or in combination with wild-type Smad4 (white bars). Bars represent mean (+/-S.E.M.) fold increases in luciferase activity normalized to the pCDNA3/-SMAD4 condition. Data were derived from three experiments performed in triplicate and were compared with two-way ANOVAs, followed by Bonferroni post-hoc tests of the significant interaction. Bars with different letters differed significantly. (B) L $\beta T 2$ cells were transfected with the $-1990 /+1 \mathrm{~m} F$ shb-luc reporter and pcDNA3, wild-type SMAD3 or SMAD3-R74K, with pcDNA3 (black bars), wild-type Smad4 (white bars), or Smad4-K88R (gray bars). Bars represent mean (+/-S.E.M.) fold increases in luciferase activity normalized to the pcDNA3/Control condition. Data were derived from two experiments performed in triplicate and were compared with one-way ANOVAs, followed by Bonferroni post-hoc test. Bars with different letters differed significantly. 
A

M - 331 CAATGGAGCCAAAGCAATGTTCAGAAAGGATTCTGAGTTCGCCA -288

H -341 GAACAGAGTCAAAGCAATACTTGGAAAGGACTCTGAATTTCCTG -298

SBE

M -287 AGTTAAAGATCAGAAA :AATA GTCTAGACCTAGAGTCACATT -245

H $\quad-297$ ATTTAAAGATACAAAAGAAAAA : : : : : : : FCTGGAGTCACAAT -262

M -244 TAATT:ACAAGGTGAGgGAgTGGGTGTGCTGCCATATCAGATT -202

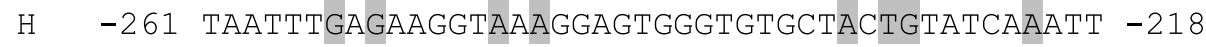

M -201 CGGTTTGTACAGAAACCATCATCACTGATAGCATT: : : : TTCT -163

H $\quad-217$ TAATTTGTACA:AAATCATCATCTCTAGTAACATTATTTTTTCT -175

M -162 GCTCTGTGGCATTTAGACTGCTTTGGCGAGGCTTGATCTCCCTG -119

H $\quad-174$ AATCTACTGCGTTTAGACTACTTTAGTAAAGCTTGATCTCCCTG -131

M $\quad-118$ TCCGTCTAAACAATGATTCCCTTTCAGCAGGCTTTATGTTGgTA -75

H $\quad-130$ TCTATCTAAACACTGATTCACTTACAGCAAGCTTCAGGCTAGCA -87

M $\quad-74$ TTGGTCATGTTAACACCCAGTAAATCCACAGGGTTTTAAGTTTG -31

H $\quad-86$ TTGGTCATATTAATACCCAACAAATCCACAAGGTGTT:AG:TTG -45

M - $\quad$ - $::::::::::$ TATAAAAGATGAGGTGAACTTGACTCAGT $\quad-1$

H $\quad-44$ CACATGATTTTGTATAAAAgGTGACTGAGATTTCATTCAGTCT -1

B

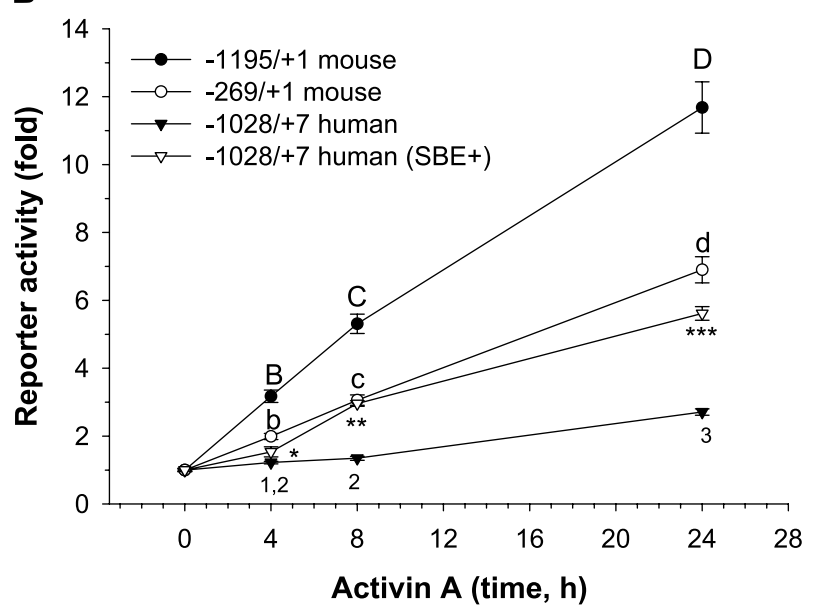

C

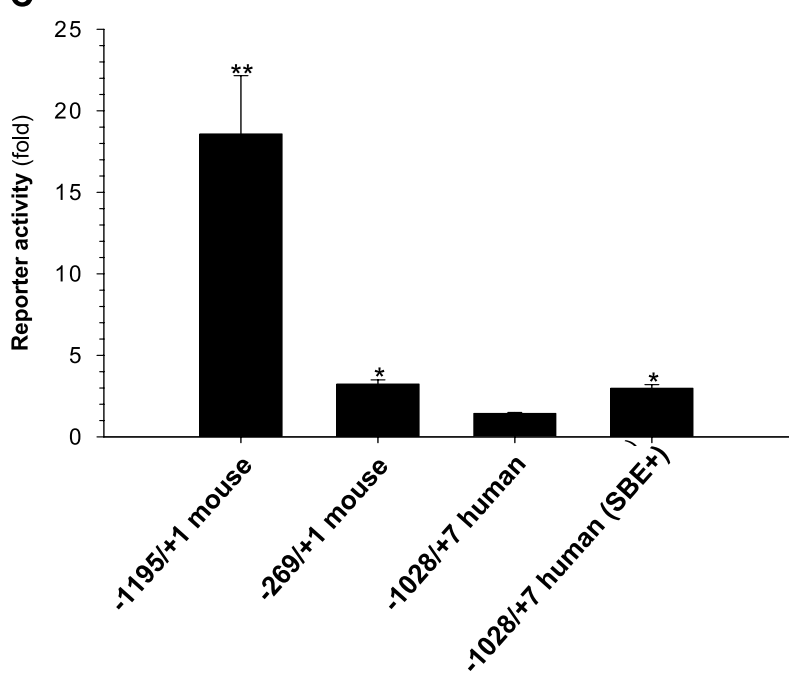

Figure 8 The human FSHB gene is not acutely regulated by activin A or stimulated by SMAD2/3/4. (A) Alignment of human $(\mathrm{H})$ and mouse $(\mathrm{M})$ proximal promoters. Bases that differ and gaps (:) are shaded. The SBE in the mouse promoter is boxed. (B) $L \beta T 2$ cells were transfected with the indicated reporter constructs and were treated with $1 \mathrm{nM}$ activin $\mathrm{A}$ for the indicated periods of time. Luciferase assays were performed as described. Points represent mean (+/- S.E.M.) fold-stimulation of luciferase activity by activin A. Because of differences in basal promoter activity with the different reporters, data were normalized to untreated cells (time 0) with the same reporter. Data were derived from two experiments performed in triplicate. Separate ANOVAs and post-hoc tests (Bonferroni) were completed for each reporter. Points with letters, numbers or asterisks differed significantly from control. Points with different letters, numbers, or number of asterisks differed from one another. (C) L $\beta$ T2 cells were transfected with the indicated reporters along with empty expression vector (pcDNA3.0) or a combination of SMAD2, 3, and 4 expression vectors. Bars represent mean (+/- S.E.M.) fold-stimulation of luciferase activity by SMAD2/3/4. Because of differences in basal promoter activity with the different reporters, data were normalized to pcDNA3.0-transfected cells with the same reporter. Data were derived from two experiments performed in triplicate. Bars with asterisks differ from the $-1028 /+7$ human reporter. The $-1195 /+1$ mouse reporter was stimulated to a greater extent than the other three reporters, ${ }^{* *}$. 
we have delineated a critical component of the molecular mechanism through which they produce this response in L $\beta$ T2 cells. Activin A stimulates the rapid phosphorylation and nuclear translocation of the R-Smads, Smad2 and Smad3 (Bernard 2004, Suszko et al. 2005). These proteins partner with the co-SMAD, SMAD4, to form complexes that can bind to a palindromic SBE in the proximal promoter at -266/ - 259. At least two complexes can bind this element: Smad3/4 and Smad2/3/4. The former appears to be more abundant, although we do not know whether this stems from differences in complex abundance, the relative affinity of the two complexes for the SBE, or the relative stability of the complexes during electrophoresis. Importantly, Smad2/3/4 complexes appear to have greater transcriptional activation function. Though, in both complexes, we predict that Smad3 and Smad4 bind to one SMAD box each within the tandem SBE. The simultaneous binding of both proteins is required for stable interaction of the complex with the element and for maximal transcriptional activation. Mutations in the SBE statistically abolish acute activin A stimulation of the promoter as well as the effects of over-expressed SMADs 2, 3, and 4. A similar SBE is observed in the rat promoter (Suszko et al. 2003, Gregory et al. 2005) and is predicted to play a comparable role in acute activin A responsiveness in that species. Collectively, these data indicate that activin A stimulates a canonical Smad-dependent pathway in LBT2 cells and direct Smad2/3/4 complex binding to the proximal promoter is critical for rapid transcriptional activation of the gene. Importantly, this mechanism is not sufficient to account for all of activins' actions, as more distal elements (and their associated trans-acting factors) are required for maximal promoter responsiveness in mice, and more chronic effects of the activins in rodents and humans may not require the direct actions of SMADs at all.

\section{SMAD2/3/4 heteromers stimulate mouse Fshb subunit transcription}

Previous studies in rat showed that SMADs 3 and 4 could interact with a comparable SBE in the Fshb promoter and that this element was required for SMAD3/4-dependent trans-activation; however, those reports did not show that these interactions were activin-regulated nor did they demonstrate that Smad2 was also contained within protein complexes interacting with this cis-element. In fact, they concluded that Smad2 was not involved in rat $F$ shb transcriptional regulation (Suszko et al. 2003, 2005, Gregory et al. 2005). Our and others' previous results implicated SMAD2 in activin A's stimulation of mouse Fshb transcription and the data presented here more clearly define its role (Dupont et al. 2003, Bernard 2004). First, RNAi experiments show that
Smad2 is required for both rapid and chronic effects of activin A on Fshb transcription (Fig. 2A). Second, gel shift and DNA precipitation assays show that activin A stimulates the formation of protein complexes containing pSmad2 that can interact with the SBE (Fig. 3). Third, over-expression experiments indicate that SMAD2 synergizes with SMADs 3 and 4 to stimulate mouse Fshb promoter activity (Fig. 4).

Although the crystal structure of SMAD2/3/4 complexes has not been solved, structures of activated SMAD2:SMAD4 and SMAD3:SMAD4 complexes were determined to be hetero-trimers with stoichiometries of 2:1 (Chacko et al. 2004). Given the high conservation of the trimer interface, however, these structures also predict the assembly of hetero-trimers containing two different R-SMADs. Though we could not definitively determine the precise number of SMAD proteins within the SBE binding complexes for technical reasons, the data we have collected thus far are consistent with the presence of one Smad3 and Smad4 each (data not shown). Based on the available structural data (Chacko et al. 2004), we predict that one Smad2 molecule is similarly contained within the complexes, though additional experimentation is required to show that Smad2/3/4 bind the SBE as hetero-trimers.

The data clearly show that the combination of SMAD2/3/4 has greater transcriptional activation function than that of SMAD3/4. Although we have not yet determined the mechanisms governing their differential effects, there are several possible explanations. For example, SMADs 2, 3, and 4 can all interact with co-activators such as p300/CBP and P/CAF (Feng et al. 1998, Janknecht et al. 1998, Nishihara et al. 1998, Pouponnot et al. 1998, Shen et al. 1998, de Caestecker et al. 2000, Itoh et al. 2000). Therefore, by virtue of having three SMADs in the complex (versus only two), more of these co-activators can potentially be recruited to the mouse Fshb promoter. Alternatively, the overall affinity of activated SMAD complexes for these co-regulatory proteins may be enhanced when SMAD2 is present. It is also possible that SMADs 2 and 3 recruit distinct co-regulators (Chou et al. 2003) and the synergistic activation we observe may be reflective of the combined actions of these different proteins.

\section{SMAD complex binding to the SBE is necessary, but not sufficient for rapid transcriptional activation by activin $A$}

Despite the clear necessity for Smad2/3/4 complexes binding to the SBE at $-266 /-259$, this mechanism does not fully account for rapid actions of activin A on mouse FSHB transcription. First, 5' deletion studies show that cis-elements between -1990 and -399 contribute almost $50 \%$ to the response of the 
$-1990 /+1$ reporter to $4 \mathrm{~h}$ activin A. The importance of these more distal elements is further underscored by experiments with the human Fshb promoter. The SBE is absent endogenously, but its' introduction increases both acute $(4-8 \mathrm{~h})$ and chronic $(24 \mathrm{~h})$ activation by activin A, as well as sensitivity to over-expressed SMADs, but not to levels attained with a mouse promoter-reporter of comparable length (Fig. 8). At the same time, the fold activin A responses of the modified human promoter are very similar to a mouse construct that lacks elements upstream of the SBE $(-269 /+1)$. Although highly conserved in their proximal promoters, the two species diverge significantly beyond $-330 /-340 \mathrm{bp}$, implicating upstream regulatory elements in activin/Smad responses in mouse. At the same time, the data presented here do not rule out the possibility that differences in the proximal promoters also contribute to inter-species variation in activin A responsiveness.

We have not yet identified the activin-responsive cis-elements within the more distal regions of the mouse promoter or the proteins that interact with them. It seems unlikely, however, that they directly bind Smads because mutation of the proximal SBE almost completely abolishes the effects of over-expressed SMADs (Fig. 5C). Rather, proteins binding more distally may interact with Smads bound to the SBE at $-266 /-259$ to confer greater activin A responsiveness both acutely and chronically. Nonetheless, we cannot reject the possibility that Smads bind to other regions of the mouse $F$ shb promoter with lower affinity.

Second, some elements within the more proximal promoter may also be required for rapid actions of activins and may interact with Smads. Although we do not observe a statistically significant stimulation of the $-257 /+1$ reporter (which lacks the canonical SBE) by activin $\mathrm{A}$, this region of the promoter does appear to be activated by $4 \mathrm{~h}$ relative to the promoter-less vector (Fig. 1B). Within this region of the sheep and mouse promoters two putative Smad boxes $(-148 /-145$ and $-115 /-112$ in mouse) have been described that contribute to activin A-stimulated transcription, though their specific roles in acute regulation were not assessed and no evidence of direct Smad binding to either site was reported (Bailey et al. 2004). We examined the -148 / - 145 element and observed very low affinity binding of recombinant SMAD3 MH1 and no SMAD4 MH1 binding at all (data not shown). Similarly, using nuclear extracts from control and activin A-treated L $\beta$ T2 cells we were unable to detect endogenous Smads binding to this element, though specific nuclear protein/DNA complexes were observed (data not shown). Nevertheless, a 2-bp mutation (AGAC to ctAG) decreased, though did not completely block, activin A-stimulated reporter activity at $4 \mathrm{~h}$ (data not shown). Thus, regardless of whether or not Smads directly interact with this cis-element, whatever proteins do bind there contributes to acute transcriptional regulation by activins and warrant further investigation.

Third, the formation of Smad2/3/4 complexes and their capacity to bind the SBE is not unique to L $\beta \mathrm{T} 2$ cells (and by extension gonadotropes), though the ability of activins to stimulate Fshb transcription is cell-specific (Pernasetti et al. 2001, Jacobs et al. 2003, Suszko et al. 2003, Bernard 2004). Here, we observe that SMAD2/ $3 / 4$ complexes that can bind the SBE can be produced through over-expression in COS7 cells or by activin A treatment in aT3-1 cells (data not shown), but endogenous $F s h b$ expression and promoter-reporter activity are not observed in these cell lines (Pernasetti et al. 2001, Bernard 2004). Thus, whereas activinstimulated Smad complexes bind the SBE to acutely regulate transcription, to exert their trans-activation function they appear to do so through interactions with co-factor proteins (Massague \& Wotton 2000) and/or by acting in a chromatin environment unique to gonadotrope cells (Yamane et al. 2005). Recently, several nuclear proteins have been implicated in Fshb expression and some appear to participate in activin-regulated transcription (Zakaria et al. 2002, Jacobs et al. 2003, Suszko et al. 2003, Aikawa et al. 2004, Bailey et al. 2004, West et al. 2004). Additional experiments are needed to more clearly define how or if these and other proteins interact with Smad complexes to rapidly regulate transcription.

\section{Acute versus chronic regulation of Fshb transcription by activins}

Our data highlight an important distinction in the control of Fshb transcription by activins that has been largely overlooked up to this point; namely that the ligand can both acutely (immediate-early) and chronically (delayed) regulate gene expression and that the underlying mechanisms may be distinct. Whereas acute activin effects in rodents appear to be strongly dependent upon canonical Smad-dependent signaling mechanisms, chronic stimulation may occur somewhat independently of Smads. For example, depletion of Smad2 or Smad3 protein levels by RNAi attenuates but does not completely block effects of $24 \mathrm{~h}$ activin A on Fshb transcription (Fig. 2) (Bernard 2004, Suszko et al. 2005). Also, mutation of the SBE in the mouse promoter abrogates the effects of over-expressed SMADs and $4 \mathrm{~h}$ activin A, but $24 \mathrm{~h}$ activin A can still significantly stimulate transcription (Fig. 5B). Finally, the human $F S H B$ promoter lacks the canonical $\mathrm{SBE}$ and is SMAD2/3/4-insensitive, but is stimulated by $24 \mathrm{~h}$ activin A (Fig. 8). These latter data suggest that activins chronically regulate the human promoter indirectly, and likely through Smad-independent mechanisms. In mouse, although the SBE and SMADs contribute to both acute and chronic activin A stimulation of 
promoter activity (Figs. 2, 5 and 8) (Suszko et al. 2003, Bernard 2004, Gregory et al. 2005), Smad-independent signaling, as in human, may contribute to delayed responses. We have not yet determined whether the mechanisms mediating chronic activin A stimulation are conserved between mouse and human.

Nonetheless, the data presented here may provide us with at least part of a molecular explanation for differential patterns of FSH regulation across rodent and human reproductive cycles. As in female rodents, women exhibit concurrent surges of $\mathrm{LH}$ and FSH secretion prior to ovulation. In addition, there is a singular rise in FSH levels during the luteal-follicular phase transition. This elevation, like the secondary surge in rodents, is required for ovarian follicular recruitment (Gougeon 1996, Schipper et al. 1998). However, in women, FSH levels begin to rise only 11-12 days after the pre-ovulatory surge and remain elevated for several days before declining during the mid to late follicular phase (Miro \& Aspinall 2005). Although the mechanisms controlling singular FSH release in women are not completely understood, existing data suggest a role for inhibins and by extension activins (Welt et al. 2002, Welt 2004, Winters \& Moore 2004).

We hypothesize that FSH synthesis and secretion during the follicular phase are chronically, but not acutely regulated because the genetic elements required for rapid, SMAD-dependent actions of activins are not present in the human FSHB promoter (e.g. the SBE and perhaps more distal cis-elements). The lack of the SBE may also contribute to the relatively low levels of FSH during this phase of the cycle (compared with secondary surge levels in rodents) given its contributions to overall activin-sensitivity of the promoter (Figs. 5B and 8B). However, the species-dependent differences we observe may be partly attributable to the fact that L $\beta \mathrm{T} 2$ is a mouse-derived cell line. As a result, co-regulatory proteins that may be needed for human FSHB expression may be lacking in these cells. This concern is somewhat tempered by the observations that the human $F S H B$ gene is both gonadotrope-restricted in its expression and hormonally responsive in the pituitaries of transgenic mice (Kumar et al. 1992, Kumar \& Low 1993, 1995). We further hypothesize that Smaddependent mechanisms observed in rodents may be required because of the unique demands of their short reproductive cycles, specifically the need to rapidly synthesize new FSH for generation of the secondary surge (see Introduction). In contrast, the long time gap between the pre-ovulatory FSH surge and FSH elevation during the luteal-follicular phase transition in women allows ample time to restore depleted intrapituitary stores, thus obviating a need for acute regulation.

From an evolutionary perspective it is interesting to contemplate whether the loss of the SBE (and other essential cis-elements) precipitated changes in the timing of female reproductive cycles or vice versa. Moreover, it will be important to examine other species to determine: 1) the extent to which acute regulation of the $F s h b$ promoter by activins is related to proximity of the primary and secondary FSH surges, and 2) whether common or distinct signaling mechanisms mediate activin responses across species. Indeed, a comparison of the proximal $F s h b$ promoters in several species, including cow, sheep, pig, human, rat and mouse indicates that the canonical SBE is present only in the rodent genes. Thus, whereas Smads are considered the prototypic signaling proteins for members of the TGFB superfamily, their roles as direct regulators of Fshb transcription may represent a specialization restricted to rodents (and perhaps other species) where the demands of the reproductive cycle require immediate-early gene activation by activins.

\section{Acknowledgements}

We thank Drs L Attisano, Y Chen, C Heldin, S Huet, RJanknecht, JJ Lebrun, J Massague, P Mellon, M Reiss, E Robertson, Y Shi, B Vogelstein and T Woodruff for generously providing reagents. Cell culture work was performed in the Cell and Tissue Culture Core Facility of the Population Council under the direction of Dr Patricia Morris and with the assistance of Marion Davis.

\section{Funding}

This work was supported by grants from the NICHD to DJB (HD047794 and HD044022). There are no conflicts of interest that would prejudice the impartiality of the presented work.

\section{References}

Ahn JM, Jung HK, Cho C, Choi D, Mayo KE \& Cho BN 2004 Changes in the reproductive functions of mice due to injection of a Plas-mid expressing an inhibin alpha-subunit into muscle: a transient transgenic model. Molecular Cells 18 79-86.

Aikawa S, Kato T, Susa T, Tomizawa K, Ogawa S \& Kato Y 2004 Pituitary transcription factor Prop-1 stimulates porcine follicle-stimulating hormone [beta] subunit gene expression. Biochemical and Biophysical Research Communications 324 946-952.

Attardi B \& Miklos J 1990 Rapid stimulatory effect of activin-A on messenger RNA encoding the follicle-stimulating hormone beta-subunit in rat pituitary cell cultures. Molecular Endocrinology 4 $721-726$.

Attisano L \& Wrana JL 2002 Signal transduction by the TGF-beta superfamily. Science 296 1646-1647.

Attisano L, Wrana JL, Montalvo E \& Massague J 1996 Activation of signalling by the activin receptor complex. Molecular \& Cellular Biology 16 1066-1073. 
Bailey JS, Rave-Harel N, McGillivray SM, Coss D \& Mellon PL 2004 Activin regulation of the follicle-stimulating hormone beta-subunit gene involves Smads and the TALE homeodomain proteins Pbxl and Prepl. Molecular Endocrinology 18 1158-1170.

Bernard DJ 2004 Both SMAD2 and SMAD3 mediate activin-stimulated expression of the follicle-stimulating hormone beta subunit in mouse gonadotrope cells. Molecular Endocrinology 18 606-623.

Besecke LM, Guendner MJ, Sluss PA, Polak AG, Woodruff TK, Jameson JL, Bauer-Dantoin AC \& Weiss J 1997 Pituitary follistatin regulates activin-mediated production of follicle-stimulating hormone during the rat estrous cycle. Endocrinology 138 2841-2848.

Bilezikjian LM, Blount AL, Leal AM, Donaldson GJ, Fischer WH \& Vale WW 2004 Autocrine/paracrine regulation of pituitary function by activin, inhibin and follistatin. Molecular \& Cellular Endocrinology 225 29-36.

Carroll RS, Corrigan AZ, Gharib SD, Vale W \& Chin WW 1989 Inhibin, activin, and follistatin: regulation of follicle-stimulating hormone messenger ribonucleic acid levels. Molecular Endocrinology 3 1969-1976.

Carroll RS, Corrigan AZ, Vale W \& Chin WW 1991 Activin stabilizes follicle-stimulating hormone-beta messenger ribonucleic acid levels. Endocrinology 129 1721-1726.

Chacko BM, Qin BY, Tiwari A, Shi G, Lam S, Hayward LJ, De Caestecker M \& Lin K 2004 Structural basis of heteromeric smad protein assembly in TGF-beta signaling. Molecular Cell $\mathbf{1 5}$ 813-823.

Chai J, Wu JW, Yan N, Massague J, Pavletich NP \& Shi Y 2003 Features of a Smad3 MH1-DNA complex. Roles of water and zinc in DNA binding. Fournal of Biological Chemistry 278 20327-20331.

Chapman SC \& Woodruff TK 2003 Betaglycan localization in the female rat pituitary: implications for the regulation of follicle-stimulating hormone by inhibin. Endocrinology 144 5640-5649.

Chou W-C, Prokova V, Shiraishi K, Valcourt U, Moustakas A, Hadzopoulou-Cladaras M, Zannis VI \& Kardassis D 2003 Mechanism of a Transcriptional Cross Talk between Transforming Growth Factor-beta -regulated Smad3 and Smad4 Proteins and Orphan Nuclear Receptor Hepatocyte Nuclear Factor-4. Molecular Biology of Cell 14 1279-1294.

Choy L \& Derynck R 2003 Transforming growth factor-beta inhibits adipocyte differentiation by Smad3 interacting with CCAAT/ enhancer-binding protein $(\mathrm{C} / \mathrm{EBP})$ and repressing $\mathrm{C} / \mathrm{EBP}$ transactivation function. Fournal of Biological Chemistry $\mathbf{2 7 8}$ 9609-9619.

Corrigan AZ, Bilezikjian LM, Carroll RS, Bald LN, Schmelzer CH, Fendly BM, Mason AJ, Chin WW, Schwall RH \& Vale W 1991 Evidence for an autocrine role of activin B within rat anterior pituitary cultures. Endocrinology 128 1682-1684.

de Caestecker MP, Yahata T, Wang D, Parks WT, Huang S, Hill CS, Shioda T, Roberts AB \& Lechleider RJ 2000 The Smad4 activation domain (SAD) is a proline-rich, p300-dependent transcriptional activation domain. Fournal of Biological Chemistry 275 $2115-2122$.

Dennler S, Huet S \& Gauthier JM 1999 A short amino-acid sequence in $\mathrm{MH} 1$ domain is responsible for functional differences between Smad2 and Smad3. Oncogene 18 1643-1648.

DePaolo LV, Hirshfield AN, Anderson LD, Barraclough CA \& Channing CP 1979 Suppression of pituitary secretion of follicle-stimulating hormone by porcine follicular fluid during pro-oestrus and oestrus in the rat: effects on gonadotrophin and steroid secretion, follicular development and ovulation during the following cycle. Fournal of Endocrinology 83 355-368.

DePaolo LV, Bald LN \& Fendly BM 1992 Passive immunoneutralization with a monoclonal antibody reveals a role for endogenous activin-B in mediating FSH hypersecretion during estrus and following ovariectomy of hypophysectomized, pituitary-grafted rats. Endocrinology 130 1741-1743.

Derynck R \& Zhang YE 2003 Smad-dependent and Smad-independent pathways in TGF-beta family signalling. Nature 425 577-584.

Dunn NR, Vincent SD, Oxburgh L, Robertson EJ \& Bikoff EK 2004 Combinatorial activities of Smad2 and Smad3 regulate mesoderm formation and patterning in the mouse embryo. Development 131 1717-1728.

Dupont J, McNeilly J, Vaiman A, Canepa S, Combarnous Y \& Taragnat C 2003 Activin signaling pathways in ovine pituitary and LbetaT2 gonadotrope cells. Biology of Reproduction $\mathbf{6 8}$ $1877-1887$.

Feng XH \& Derynck R 2005 Specificity and Versatility in TGFSignaling Through Smads. Annual Reviews in Cell Development and Biology.

Feng XH, Zhang Y, Wu RY \& Derynck R 1998 The tumor suppressor Smad4/DPC4 and transcriptional adaptor CBP/p300 are coactivators for smad3 in TGF-beta-induced transcriptional activation. Genes Development 12 2153-2163.

Gougeon A 1996 Regulation of ovarian follicular development in primates: facts and hypotheses. Endocrine Reviews 17 121-155.

Gregory SJ \& Kaiser UB 2004 Regulation of gonadotropins by inhibin and activin. Seminars in Reproductive Medicine 22 253-267.

Gregory SJ, Lacza CT, Detz AA, Xu S, Petrillo LA \& Kaiser UB 2005 Synergy between activin A and gonadotropin-releasing hormone in transcriptional activation of the rat follicle-stimulating hormone-beta gene. Molecular Endocrinology 19 237-254.

Halvorson LM, Weiss J, Bauer-Dantoin AC \& Jameson JL 1994 Dynamic regulation of pituitary follistatin messenger ribonucleic acids during the rat estrous cycle. Endocrinology 134 1247-1253.

Hoak DC \& Schwartz NB 1980 Blockade of recruitment of ovarian follicles by suppression of the secondary surge of follicle-stimulating hormone with porcine follicular field. PNAS 77 4953-4956.

Hoffmann JC, Lorenzen JR, Weil T \& Schwartz NB 1979 Selective suppression of the primary surge of follicle-stimulating hormone in the rat: further evidence for folliculostatin in porcine follicular fluid. Endocrinology 105 200-203.

Horton RM, Cai ZL, Ho SN \& Pease LR 1990 Gene splicing by overlap extension: tailor-made genes using the polymerase chain reaction. Biotechniques 8 528-535.

Huang HJ, Sebastian J, Strahl BD, Wu JC \& Miller WL 2001 The promoter for the ovine follicle-stimulating hormone-beta gene (FSHbeta) confers FSHbeta-like expression on luciferase in transgenic mice: regulatory studies in vivo and in vitro. Endocrinology 142 2260-2266.

Itoh S, Ericsson J, Nishikawa J, Heldin CH \& ten Dijke P 2000 The transcriptional co-activator P/CAF potentiates TGF-beta/Smad signaling. Nucleic Acids Research 28 4291-4298.

Jacobs SBR, Coss D, McGillivray SM \& Mellon PL 2003 Nuclear Factor Y and Steroidogenic Factor 1 Physically and Functionally Interact to Contribute to Cell-Specific Expression of the Mouse Follicle-Stimulating Hormone-\{beta\} Gene. Molecular Endocrinology 17 1470-1483.

Janknecht R, Wells NJ \& Hunter T 1998 TGF-beta-stimulated cooperation of smad proteins with the coactivators $\mathrm{CBP} / \mathrm{p} 300$. Genes Development 12 2114-2119.

Kumar TR \& Low MJ 1993 Gonadal steroid hormone regulation of human and mouse follicle stimulating hormone beta-subunit gene expression in vivo. Molecular Endocrinology 7 898-906.

Kumar TR \& Low MJ 1995 Hormonal regulation of human follicle-stimulating hormone-beta subunit gene expression: GnRH stimulation and GnRH-independent androgen inhibition. Neuroendocrinology 61 628-637.

Kumar TR, Fairchild-Huntress V \& Low MJ 1992 Gonadotrope-specific expression of the human follicle-stimulating 
hormone beta-subunit gene in pituitaries of transgenic mice. Molecular Endocrinology 6 81-90.

Layman LC \& McDonough PG 2000 Mutations of follicle stimulating hormone-beta and its receptor in human and mouse: genotype/phenotype. Molecular \& Cellular Endocrinology 161 9-17.

Levine J 1997 New concepts of the neuroendocrine regulation of gonadotropin surges in rats. Biology of Reproduciton 56 293-302.

Levy L \& Hill CS 2005 Smad4 dependency defines two classes of transforming growth factor $\{$ beta $\}$ (TGF- $\{$ beta $\}$ ) target genes and distinguishes TGF-\{beta $\}$-induced epithelial-mesenchymal transition from its antiproliferative and migratory responses. Molecular \& Cellular Biology 25 8108-8125.

Massague J \& Wotton D 2000 Transcriptional control by the TGF- $\{$ beta $\} /$ Smad signaling system. EMBO fournal 19 $1745-1754$

Miro F \& Aspinall LJ 2005 The onset of the initial rise in follicle-stimulating hormone during the human menstrual cycle. Human Reproduction 20 96-100.

Moren A, Itoh S, Moustakas A, Dijke P \& Heldin CH 2000 Functional consequences of tumorigenic missense mutations in the amino-terminal domain of Smad4. Oncogene 19 4396-4404.

Nakao A, Imamura T, Souchelnytskyi S, Kawabata M, Ishisaki A, Oeda E, Tamaki K, Hanai J-i, Heldin C-H, Miyazono K et al. 1997 TGF-beta receptor-mediated signalling through Smad2, Smad3 and Smad4. EMBO Journal. 16 5353-5362.

Nequin LG, Alvarez J \& Schwartz NB 1979 Measurement of serum steroid and gonadotropin levels and uterine and ovarian variables throughout 4 day and 5 day estrous cycles in the rat. Biology of Reproduction 20 659-670.

Nicol L, McNeilly, JR, Stridsberg M \& McNeilly A 2004 Differential secretion of gonadotrophins: investigation of the role of secretogranin II and chromogranin A in the release of $\mathrm{LH}$ and FSH in LbetaT2 cells. Fournal of Molecular Endocrinology 32 467-480.

Nishihara A, Hanai JI, Okamoto N, Yanagisawa J, Kato S, Miyazono K \& Kawabata M 1998 Role of p300, a transcriptional coactivator, in signalling of TGF-beta. Genes Cells $\mathbf{3}$ 613-623.

Niwa H, Yamamura K \& Miyazaki J 1991 Efficient selection for high-expression transfectants with a novel eukaryotic vector. Gene 108 193-199.

Ortolano GA, Haisenleder DJ, Dalkin AC, Iliff-Sizemore SA, Landefeld TD, Maurer RA \& Marshall JC 1988

Follicle-stimulating hormone beta subunit messenger ribonucleic acid concentrations during the rat estrous cycle. Endocrinology 123 2946-2948.

Pernasetti F, Vasilyev VV, Rosenberg SB, Bailey JS, Huang HJ, Miller WL \& Mellon PL 2001 Cell-specific transcriptional regulation of follicle-stimulating hormone-beta by activin and gonadotropin-releasing hormone in the LbetaT2 pituitary gonadotrope cell model. Endocrinology 142 2284-2295.

Pouponnot C, Jayaraman L \& Massague J 1998 Physical and functional interaction of SMADs and p300/CBP. Fournal of Biological Chemistry 273 22865-22868.

Roberts V, Meunier H, Vaughan J, Rivier J, Rivier C, Vale W \& Sawchenko P 1989 Production and regulation of inhibin subunits in pituitary gonadotropes. Endocrinology 124 552-554.

Schipper I, Hop WCJ \& Fauser BCJM 1998 The FollicleStimulating Hormone (FSH) Threshold/Window Concept Examined by Different Interventions with Exogenous FSH during the Follicular Phase of the Normal Menstrual Cycle: Duration, Rather Than Magnitude, of FSH Increase Affects Follicle Development. Fournal of Clinical Endocrinology \& Metabolism 83 $1292-1298$

Shen X, Hu PP, Liberati NT, Datto MB, Frederick JP \& Wang XF 1998 TGF-beta-induced phosphorylation of Smad3 regulates its interaction with coactivator p300/CREB-binding protein. Molecular Biology of Cell 9 3309-3319.
Shi Y, Wang YF, Jayaraman L, Yang H, Massague J \& Pavletich NP 1998 Crystal structure of a Smad MHl domain bound to DNA: insights on DNA binding in TGF-beta signaling. Cell $\mathbf{9 4}$ 585-594.

Suszko MI, Lo DJ, Suh H, Camper SA \& Woodruff TK 2003 Regulation of the rat follicle-stimulating hormone beta-subunit promoter by activin. Molecular Endocrinology 17 318-332.

Suszko MI, Balkin DM, Chen Y \& Woodruff TK 2005 Smad3 mediates activin-induced transcription of follicle-stimulating hormone \{beta\}-subunit gene. Molecular Endocrinology 19 1849-1858.

Tejada F, Cremades A, Aviles M, Castells MT \& Penafiel R 1998 Hypokalemia alters sex hormone and gonadotropin levels: evidence that FSH may be required for luteinization. American Fournal of Physiology 275 E1037-1045.

Themmen APN \& Huhtaniemi IT 2000 Mutations of gonadotropins and gonadotropin receptors: elucidating the physiology and pathophysiology of pituitary-gonadal function. Endocrine Reviews 21 551-583.

Therrien M \& Drouin J 1993 Cell-specific helix-loop-helix factor required for pituitary expression of the pro-opiomelanocortin gene. Molecular \& Cellular Biology 13 2342-2353.

Tsuchida K, Nakatani M, Yamakawa N, Hashimoto O, Hasegawa Y \& Sugino H 2004 Activin isoforms signal through type I receptor serine/threonine kinase ALK7. Molecular \& Cellular Endocrinology $22059-65$.

von Gersdorff G, Susztak K, Rezvani F, Bitzer M, Liang D \& Bottinger EP 2000 Smad3 and Smad4 Mediate Transcriptional Activation of the Human Smad7 Promoter by Transforming Growth Factor beta. Fournal of Biological Chemistry $\mathbf{2 7 5}$ 11320-11326.

Weiss J, Guendner MJ, Halvorson LM \& Jameson JL 1995 Transcriptional activation of the follicle-stimulating hormone beta-subunit gene by activin. Endocrinology 136 1885-1891.

Welt CK 2004 Regulation and function of inhibins in the normal menstrual cycle. Seminars in Reproductive Medicine 22 187-193.

Welt CK, Sidis Y, Keutmann H \& Schneyer A 2002 Activins, Inhibins, and Follistatins: From Endocrinology to Signaling. A Paradigm for the New Millennium. Experimental Biology and Medicine 227 724-752.

West BE, Parker GE, Savage JJ, Kiratipranon P, Toomey KS, Beach LR, Colvin SC, Sloop KW \& Rhodes SJ 2004 Regulation of the Follicle-Stimulating Hormone \{beta\} Gene by the LHX3 LIM-Homeodomain Transcription Factor. Endocrinology 145 4866-4879.

Winters SJ \& Moore JP 2004 Intra-pituitary regulation of gonadotrophs in male rodents and primates. Reproduction 128 $13-23$.

Woodruff TK 1998 Regulation of cellular and system function by activin. Biochemistry \&O Pharmacology 55 953-963.

Woodruff TK, Besecke LM, Groome N, Draper LB, Schwartz NB \& Weiss J 1996 Inhibin A and inhibin B are inversely correlated to follicle-stimulating hormone, yet are discordant during the follicular phase of the rat estrous cycle, and inhibin $\mathrm{A}$ is expressed in a sexually dimorphic manner. Endocrinology $1375463-5467$.

Yagi K, Goto D, Hamamoto T, Takenoshita S, Kato M \& Miyazono K 1999 Alternatively spliced variant of Smad2 lacking exon 3. Comparison with wild-type Smad2 and Smad3. Fournal of Biological Chemistry 274 703-709.

Yamane K, Suzuki H, Ihn H, Kato M, Yoshikawa H \& Tamaki K 2005 Cell type-specific regulation of the TGF-beta-responsive alpha2(I) collagen gene by CpG methylation. Fournal of Cell Physiology 202 822-830.

Yang YC, Piek E, Zavadil J, Liang D, Xie D, Heyer J, Pavlidis P, Kucherlapati R, Roberts AB \& Bottinger EP 2003 Hierarchical model of gene regulation by transforming growth factor beta. PNAS 100 10269-10274. 
Zakaria MM, Jeong KH, Lacza C \& Kaiser UB 2002 Pituitary homeobox 1 activates the rat FSHbeta (rFSHbeta) gene through both direct and indirect interactions with the rFSHbeta gene promoter. Molecular Endocrinology 16 1840-1852.

Zawel L, Dai JL, Buckhaults P, Zhou S, Kinzler KW, Vogelstein B \& Kern SE 1998 Human Smad3 and Smad4 are

sequence-specific transcription activators. Molecular Cell 1 611-617.
Zhang Y, Feng X, We R \& Derynck R 1996 Receptor-associated Mad homologues synergize as effectors of the TGF-beta response. Nature 383 168-172.

Received 3 November 2005

Accepted 18 November 2005

Made available online as an Accepted Preprint 25 November 2005 